\title{
Method for Determining
}

the Resolving Power of

Photographic Lenses

\section{UNITED STATES DEPARTMENT OF COMMERCE}

NATIONAL BUREAU OF STANDARDS 
Additional sets of the new NBS lens resolution charts (1 sheet of 6 high-contrast and 1 sheet of 6 low-contrast charts) may be purchased from the Superintendent of Documents, U. S. Government Printing Office, Washington 25, D. C. These are published as "Supplement to NBS Circular 533."

Price 75 cents

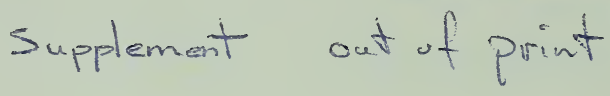




\section{Method for Determining the Resolving Power of Photographic Lenses}

Francis E. Washer and Irvine C. Gardner

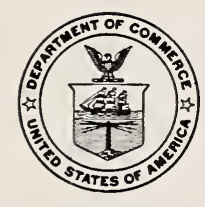

National Bureau of Standards Circular 533

Issued May 20, 1953

(Supersedes Circular 428)

For sale by the Superintendent of Documents, U. S. Government Printing Office, Washington 25, D. C. 



\section{PREFAGE}

The purpose of this Circular is to present a method for determining the relative performance of photographic lenses based on their image-forming qualities. The method is sufficiently simple to permit its application by the arerage amateur photographer with the equipment that he normally has available or may readily obtain. In addition, the Circular contains information relating to interpretation of test results that may be useful to the professional photographer.

This Circular supersedes NBS Circular 428, A Test of Lens Resolution for the Photographer. It includes the information contained in Circular 428, together with additional material based upon work done between 1940 and 1952 . It is believed that this Circular will prove a useful reference for all those engaged in preparing specifications that include requirements related to image quality.

A. V. Astin, Director. 


\section{Contents}

Preface

1. Introduction

2. Choice of criterion for judging a lens

3. Speed of a lens as a criterion $\ldots 2$

4. Quality of definition as a criterion _... 3

5. Significance of a resolving-power test $\ldots \ldots$

6. Charts for testing resolving power

7. NBS resolution test chart of $1952 \ldots 5$

7.1. Description

7.2. Metrical characteristics__._._. 6

7.3. Range of chart at the standard distance $\ldots \ldots \ldots$

7.4. Methods of extending chart range _................ 7

(a) Change of lens to target distance............... 8

(b) Change of chart size by photographic means_...... 8

7.5. Method of changing length of line patterns _......... 10

8. Details of camera test $\ldots \ldots \ldots$

8.1. Arrangement of charts _......... 10

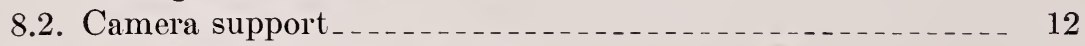

8.3. Use of multiple rows of charts $\ldots \ldots 13$

(a) Determination of focusing error 14

8.4. Illumination of charts _._.

8.5. Methods of focusing _._.

(a) Focusing by means of coupled range finder _....... 16

(b) Focusing by means of focusing back _.......... 17

(c) Focusing by means of focusing scale _........... 17

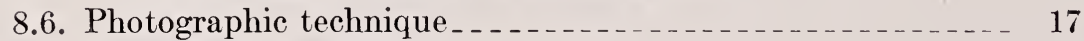

8.7. Examination of negative _... 18

9. Interpretation of results _._.

9.1. Maximum resolving power of an ideal lens _......... 18

9.2. Depth of focus for an ideal lens

9.3. Effect of field curvature _.......................... 20

9.4. Experimental results for actual lenses _..._._.

(a) Experimental results with high-contrast chart_...... 22

(b) Comparative results on axis for high- and low-contrast

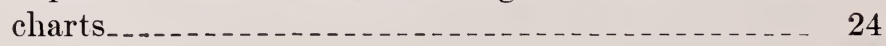

10. Additional uses of test chart _.

10.1. Test for goggles and sunglasses $\ldots \ldots \ldots \ldots$

(a) Prismatic power

(b) Refractive power of goggles

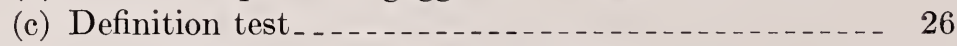

10.2. Resolution test for telescopes and binoculars _......... 26

11. References_......... 27 


\title{
Method for Determining the Resolving Power of Photographic Lenses
}

\author{
Francis E. Washer and Irvine C. Gardner
}

\begin{abstract}
This Circular provides the photographer with two sets of charts by which the resolving power of a photographic lens may be numerically measured with respect to a definite scale of values. A detailed description is given of the procedure and technique to be followed in order that comparable values may be obtained by different observers. The test provides an objective method of testing a photographic lens. The six charts of one set are printed in black ink on a white background to form a high-contrast chart. The six charts of the other set are printed with gray ink on a gray background to form a low-contrast chart. Additional uses of these charts are also described. These uses include the testing of goggle lenses for definition and prismatic power and the testing of telescopes and binoculars for definition.
\end{abstract}

\section{Introduction}

In 1940, National Bureau of Standards Cireular $428[1],{ }^{2}$ "A test of lens resolution for the photographer," was published. This Circular, in addition to giving detailed instructions for performing a lens resolution test, also contained 12 carefully made test charts for use in the test. These test charts were made by the Bureau of Engraving and Printing in accordance with detailed specifications relating to width of lines and steps between patterns. Use of the process identical with that employed in printing postage stamps insured exact duplications of the test patterns. This test chart has been of immense value during the past 12 years to large numbers of people engaged in work that required an accurately made test pattern. It has been helpful also in that it prorided workers in various parts of the country with a test chart common to all and made easier comparison of results obtained in widely separated laboratories.

The Circular with its accompanying test chart, together with a companion publication [2] consisting of test charts only, had been prepared initially with the intent of being a useful tool for the amateur photographer, in that it provided him with a device with which he could test and rate the lenses on his own cameras. Judging from the extensive sales of the Circular, it has performed its intended function. In addition, however, it has found use in the testing of a variety of optical equipment, such as telescopes, binoculars, goggle lenses, and sunglass lenses.

During the past 12 years, there have been considerable gains in the science of applied optics, particularly in the field of lens resolution, and it therefore seemed desirable to prepare a revision of Circular 428 and to include in this revision some

1 The work described in this paper was supported in part by the United States Air Force and the United States Army Signal Corps.

${ }^{2}$ Figures in brackets indicate the literature references at the end of this paper. aspects of the more recent gains in knowledge. Some of the principal changes are in the nature of the test chart itself. It has been found that a multiplicity of lines in a given pattern makes it needlessly difficult to decide whether or not a given pattern is resolved. This is especially important in visual determinations where a common criterion of resolution is that the line count shall be the same for a given pattern in the image as in the object. The charts, presented here, have only three lines per pattern in all patterns, thus simplifying the process of checking line count in the image against line count in the object. In order to achieve greater precision in the rating of lenses, the ratio of change of size between patterns has been reduced from the $\sqrt{ } 2$ to the $\sqrt[4]{2}$.

The range of the present charts is from 12 to 80 lines $/ \mathrm{mm}$ as contrasted with 3.5 to 56 lines $/ \mathrm{mm}$ on the old chart. While this represents an increase at the higher end, it eliminates the directreading range from 3.5 to 10 . This, howerer, has been compensated by a procedure through which values of resolving power for the range 3.6 to 14 lines $/ \mathrm{mm}$ can be approximated by consideration of entire groups. While the chart is primarily intended for use in the visual analysis of lens performance, the length of the target lines and their positions with respect to one another have been so chosen that the imagery can be studied with commercially available types of recording microdensitometers. The charts in this new Circular are provided in two contrasts. The highcontrast charts have black lines on a white background, and the low-contrast charts have gray lines on a gray backiround.

All the information on lens performance that could be obtained by the user with the charts contained in NBS Circular 428 can also be obtained with the charts contained in the present Circular, so that these charts can be used in their stead without difficulty. In addition, it is believed that the new features in these charts will make them still more useful than the earlier charts contained in Circular 428. 


\section{Choice of Criterion for Judging a Lens}

The question of how to rate the performance of a lens is necessarily complex, depending as it does upon the use of the lens. The complexity of the problem can be somewhat reduced by confining the scope of this article to the questions that confront the user who is interested primarily in pictorial quality and who is not concerned with using the resultant negatives for precision measurements such as are required in cartography and photolithography. It is believed that most camera users, outside the strictly professional field, are concerned with such matters as lens speed and quality of definition, with the latter being of prime concern.

\section{Speed of a Lens as a Criterion}

The speed of a lens, as determined by its maximum relative aperture, is heavily emphasized in most discussions pertaining to lens performance. It also receives the most emphasis in sales literature. This emphasis arises from a variety of causes. Perhaps this is chiefly because the speed of a lens is one of the fer chracteristics for which a definite numerical system of measurement has been fairly well established. Among seriously minded photographers the speed of a lens is of prime importance in that the greater light gathering power of a high-speed lens permits good pictures to be obtained under adverse lighting conditions.

The expression "speed" as applied to a lens is essentially a colloquialism which has been to some extent justified by long usage. It is not a speed in the accepted sense of expressing a rate of change with time, but is rather a measure of the light gathering ability of a lens. Most photographers are at times constrained to use as short an exposure time as possible, either to stop motion in the subject or to avoid blurring arising from camera morement, and it is obvious that a lens having greater light gathering ability permits the use of a shorter exposure time than that required for a lens haring lesser light-gathering ability. Consequently, it is fairly natural to refer to this property as "speed." Actually, the light-gathering ability of a lens is determined by the amount of light passing through the lens that reaches a given area of the image plane. This quantity is measured by the light flux contained in a cone, the tip of which is in the image plane and the base of which is the clear opening of the lens. If, for two lenses having the same cone height, one has twice the base area, then twice the amount of light reaches the image plane and the one lens has twice the light-gathering ability. For a circular lens opening, it is clear that the ratio of the 2 diameters of the cone bases in the above illustration is $\sqrt[2]{2}$, or 1.4 . The maximum aperture of a lens is customarily expressed in terms of the focal length, the expression $f / 4.5$ signifying that the diameter of the effective aperture is equal to the equivalent focal length divided by 4.5 . (In the above, simple illustration, the cone height is the focal length, and the diameter of the cone base is the effective aperture.) The aperture of a lens, expressed in terms of focal length in this manner, is referred to as the relative aperture. The number in the denominator is sometimes referred to as the $f$-number. On changing the stop openings of a given lens, the light flux reaching the image plane is inversely proportional to the square of the $f$-number. Consequently, if the stop is set at $f / 4$ and the exposure time is $1 / 100$ second, then it will be necessary to use double this exposure time, or $1 / 50$ second, when the lens is set at $f / 5.6$. It must be remembered that the $f$-numbers marked on a lens are determined for large object distances.

It should be noted that the maximum relative aperture of a lens does not completely determine the effective speed. For lenses of the same maximum relative aperture, and consequently of the same nominal speed, variations of the effective speed may arise from differences in the number of glass-air surfaces. The Tessar type of lens has 3 separated components and consequently 3 pairs of glass-air surface. A modern $f / 2$ lens may have 5 separated components with 5 pairs of glass-air surfaces. Each pair of surfaces entails a loss of from 8 to 10 percent of the light incident upon the surface. If, therefore, the Tessar lens and the $f / 2$ lens are set to the same stop opening, the Tessar lens will transmit approximately 20 percent more light than the $f / 2$ lens. This difference is not serious when the camera is used with an emulsion having considerable latitude, although by virture of multiple reflections some of this lost light may eventually reach the emulsion as nonimage forming light and contribute to the overall haze, thus reducing the contrast of the pictures. In extreme cases, these multiple reflections may produce ghosts.

In recent vears, the use of low-reflection films on the glass-air surfaces has resulted in marked reduction of the light losses. When the glassair surfaces have been so treated, the loss per pair of surfaces may fall as low as from 3 to 4 percent of the light. Consequently, the differences between treated lenses are not so pronounced. However, good lenses are in use that either from choice were not coated at the time of manufacture or were made prior to the development of the low-reflection process. Most coated lenses have transmittances in excess of 80 percent and may run as high as 90 percent. Transmittances for uncoated lenses vary from 60 to 80 percent, depending upon the number of pairs of glass-air surfaces. It is therefore obvious that speed differences between lenses of same stop opening may be as high as one-third stop opening from the above causes alone. Attempts have been made in recent years to alleviate this situation 
by calibrating lenses in terms of the transmittance of an ideal lens that would transmit 100 percent of the light $[3,4]$. Such lenses are marked in $T$-stops instead of the more familiar $f$-stops. This system has the great advantage that the speed ratings of all types of lenses become directly comparable. It is unlikely that the transmittances that have been carefully calibrated according to the $T$-stop system will show variations in excess of \pm 10 percent, regardless of type of lens, coated or uncoated.

This $T$-stop system does have two minor disadvantages. The first is that the $T$-numbers are always larger than the $f$-numbers. A lens having an $f$-number of 2 may have a $T$-number of 2.2 . This may give rise to some misunderstandings if one happens to confuse the $f$-number and $T$-number system of marking. 'This will prove to be a minor' handicap, as more and more people become conversant with the $T$-number system. A second nominal disadvantage is the fact that the familiar tables containing depth of field data would be subject to some error as the computations of these tables are based on the geometric $f$-number. If the geometric $f$-number were to be wholly superseded by the T-number, some error would result in estimating depth of field if the $T$-number were used without appropriate corrections. This error is too small to be important.

Lenses of different types or makes may show important differences in performance arising from differences in the vignetting. For a given setting of the diaphragm the effective exposure is necessarily less at the corners of a photographic plate than at the center. However, in order to produce a compact lens suitable for a hand camera of reduced size, or in order to lessen the cost of production, the outer components of the lens, in some instances, are unduly reduced in diameter. When this is done, the speed of the lens, so far as the center of the plate is concerned, is not reduced, but there is excessive rignetting, and the exposure received by the corners of the plate is much less than for a lens having the same normal speed but with the outer components of a more generous diameter. With black-and-white film the latitude of the emulsion in most cases, masks the effect of excessive rignetting, and the performance of the lens is reasonably satisfactory. With films of limited latitude, such as color films, the effect of excessive vignetting is more pronounced and may be sufficient to make the resulting pictures quite unsatisfactory. This excessive rignetting, when present, is effective only for the larger diaphragm openings. As the lens is stopped down, the Illumination over the field becomes more uniform.

In general, while speed of a lens is an important criterion in its selection, it is not one that can be readily checked by the purchaser. However, the speed markings are usually sufficiently reliable that the prospective user need not be overly concerned. The principal point is to check for excessive vignetting, which can be done by photo- graphing a uniformly lighted area with the diaphragm opened wide and noting whether or not there is marked variation in the density of the negative from center to corner. When the change in density from center to corner is as great as 0.6 , it is probable that the pictures will be noticeably inferior to those where the change in density from center to corner is less than 0.3 .

\section{Quality of Definition as a Criterion}

For most purposes it appears that the production of a sharp, crisp image is the indispensable attribute of a lens. The present prevalent practice of making enlargements of several diameters from the original negative has created a general demand for lenses giving sharper and better defined images than were considered satisfactory some years ago. A great variety of photographic lenses are now available, and lenses identical in focal length and speed but of different makes and qualities sell at widely different prices. When such a series of lenses is tested, the most marked difference in performance is found to lie in the varying sharpness of the image produced, and this one characteristic is probably the best single criterion for determining the quality of a lens.

In advertising literature the lens makers have not yet adopted a method of specifying the quality of their lenses that is helpful to the purchaser. This is not surprising, because a precise specification of lens quality is attended with many difficulties. It is common practice to describe a lens as being free or sensibly free from the different aberrations, such as chromatic and spherical aberration, coma, astigmatism, curvature, and distortion. No lens can be entirely free from these aberrations. Furthermore, in any lens that covers an extended field of view, some of the aberrations are always present to such an extent that they are sensible at some part of the field, either on a contact print or on an enlargement of four or five diameters. Even if the engineering procedure of giving graphs showing the magnitudes of the aberrations at all points of the field were adopted, it would still be difficult to formulate an opinion of the relative quality of two lenses having different aberrations.

Lenses are sometimes characterized by a statement that the diameter of the circle of confusion is one one-hundredth or one two-hundred-and-fiftieth of an inch. This method of description appears to be a quantitative one, but it does not give complete information. A measurement of the circle of confusion offers peculiar difficulties. If the measurement is made on the photographic image of a star, real or artificial, the diameter of the recorded image is so largely a function of the brightness of the star and the duration of the exposure that it tells little about the performance of the lens. In fact, the astronomer customarily measures the diameter of a star image in order to determine the brightness of the star. Definite 
tatements regarding the method by which the diameter of the circle of confusion is measured are not generally made, but it appears probable that the values listed are commonly based upon the results of ray tracing by mathematical computations that are required for the development of the design of the lens. If this is the case, the diameter of the circle of confusion is a test of the excellence of the lens design and does not fully indicate the performance of the finished lens.

It will be readily appreciated that a good design is a prerequisite for the construction of a good lens, but it will also be appreciated that good workmanship and careful control during the making of the lens are equally important. A method of specifying a lens that does not give weight to the quality of workmanship is not a suitable criterion of the excellence of a lens.

In connection with the testing of airplane camera lenses over a period of years, the National Bureau of Standards has had the opportunity of studying the suitability of a measurement of the resolving power of a lens as a method of specifying its quality of definition. An elaborate testing device $[5,6,7]$ for measuring the resolving power has been built, and all airplane camera lenses that are to be used on Government mapping projects must be tested upon this instrument. Because it does not appear practicable for the National Bureau of Standards to undertake the general testing of hand cameras for the public or to publish comparative ratings of the different lenses, a modified method of making a resolving-power test has been developed. This simplified test can be made by means of apparatus that the camera user can readily improvise, and can be conducted by one skilled in photographic technique to the extent that is required for the successful operation of a miniature camera.

\section{Significance of a Resolving-Power Test}

The test comprises a measure of the resolving power of the lens and camera combination, a characteristic that determines the sharpness of the image and the degree to which it can be enlarged. If one attempts to photograph a pattern of parallel lines, it will be found that the lines, if too close together, will photograph as a gray patch, and the individual lines cannot be distinguished. If, however, the lines in the object are so far apart that the lens records them as distinct lines, the lens is said, in optical parlance, to resolve the lines.

We can, therefore, give considerable information regarding the quality of definition of a lens by a statement regarding the finest pattern of lines that it resolves. A given pattern of lines will appear finer and be more difficult to resolve as it is placed more distant from the lens. Consequently, if the distance between just-resolvable lines on the test chart is measured, this tells nothing of the performance of the lens unless the distance from lens to chart is also measured. This introduces a certain amount of complication, which could be less- ened somewhat if the separations of the lines were given in angular instead of linear measure.

Actually, however, one is usually concerned, not with the fineness of detail in the object but with the fineness of detail upon the negative or the finished print. A large picture, or a small picture, when examined for quality of definition is scrutinized from the distance of best seeing or perhaps examined with a hand lens, and it is commonly desired that the pictures be equally sharp, regardless of size. From an artistic standpoint, there may be much to be said against this criterion, but nevertheless the user of a lens commonly expects the negative to be of approximately the same sharpness, regardless of its size or the focal length of the lens. In view of this, it is desirable to base the determination of resolving power upon a measurement of the image. In accordance with the established practice, the number of lines per millimeter, measured on the negative, of the finest pattern resolved will be used as a measure of the resolving power. As an illustration, if the resolving power is given as 40 , lines spaced 40 to the millimeter (the distance between the centers of the adjacent lines in such a case, is one-thousandth of an inch, or 25 microns) upon the negative are distinguishable as separate and distinct lines.

It should be mentioned that the resolution test, when conducted as described, is dependent not only upon the lens but also upon the camera construction and the characteristics of the photographic film. A lens cannot be expected to produce negatives of the first quality unless it is mounted in a camera that holds the film, free from curvature, in a plane normal to the axis of the lens and in perfect focus. Furthermore, consistently good negatives cannot be produced unless the camera movements are sufficiently free from lost motion to permit a given adjustment to be repeated with certainty. Even with an excellent lens and camera, the resolution may be limited by the type of film that is used. With the better lenses, the limiting resolution in the center of the field is usually determined by the film rather than by the lens. Consequently, when testing a lens, the use of the finest grain film that is commercially available is recommended in order that the potential resolution of the lens may be more closely approximated. Care should be taken to insure that the spectral range of sensitivity of the film. used for test be approximately the same as that of the film that is normally used in the camera. If a finegrain orthochromatic emulsion is used, the results may be affected by the difference in spectral sensitivity and consequently should not be used directly as a basis for judging probable performance of the lens when used with a panchromatic emulsion.

\section{Charts for Testing Resolving Power}

The ability of a lens to produce clear-cut images of an object containing fine details has long been accepted as a principal factor in judging lens performance. This property is closely associated 
with the resolving power of the lens, and throughout the rears considerable thought has been deroted to the design of various trpes of test charts. In general, the various types of charts provide the user with an array of patterns arranged in a series of diminishing size in accordance with some predetermined ratio. The chart dereloped at this Bureau in the early 1930's and used as the basis of designing the test chart that was contained in Circular 428 was of this type.

This chart is shown in figure 1. It consists of a series of line patterns of such sizes that when photographed at a $25 \times$ reduction, the numbers identifying the pattern give the resolving power of the lens-emulsion combination directly in lines per millimeter. The ratio of the line spacings in the patterns between adjacent nembers in the series is approximately $1.4(=\sqrt{ } 2)$. This chart has proved quite successful throughout its rears of service. However, improvements have been suggested that would extend its usefulness.

Several lines of approach to the measurement of resolving power have developed in recent years, and it is worthwhile to recount a few of the new concepts and recommendations that have come into being as a result. The phenomenon of false resolving power $[6,8]$, as it affects the study of lens performance, has given rise to the idea that fewer lines in a given pattern would make its detection easier, since in one of its manifestations the line count in the image differs from that in the object for a given pattern. This has led to the development of the three-line pattern [9] currently used by the U. S. Air Force. Further simplification was accomplished by the British group [10], where the 2-line, or Cobb, chart was adopted.

The belief that the interval between adjacent members of the series of test patterns should be smaller has led to the use of such ratios of line spacings as $1.26(=\sqrt[3]{2})$ and $1.12(=\sqrt[6]{2})$. In their resolution charts, the $U$. S. Air Force used the $\sqrt[3]{2}$ ratio initially and is now using the $\sqrt[6]{2}$ ratio. The $\sqrt[6]{2}$ ratio is used in the Cobb chart preferred by the British group. A completely different type of test pattern was dereloped in Canada [11] consisting of a series of annular rings which purports to give greater weight to "edge effects."

The effect of contrast of the object has formed the subject of numerous investigations $[9,10,11$, $12,13]$, and several of the test charts are designed to be used at relatively low contrast. It is undeniably true that contrast plays an important part in the eraluating of lens performance, and numerous investigations are now in progress that deal with this subject.

In the 3-line and 2-line targets mentioned, the ratio of line length to line width is held constant from pattern to pattern on the assumption that allowing this ratio to vary introduces an element of uncertainty into the determinations.

It is clear from the foregoing cursory discussion that a great deal of work has been done in recent rears on the subject of resolving power, and further

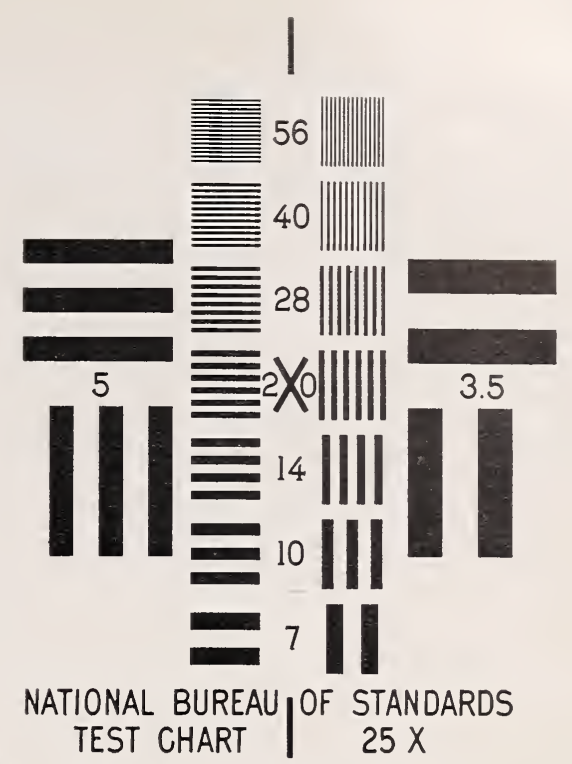

FigURE 1. High-contrast resolution test chart formerly used.

This chart formed part of NBS Circular 428. The ratio of the line spacings in successive patterns of this chart is equal to $\sqrt{2}$. When the chart is photographed at the standard distance of $26 f$, the values of resolving power that can be measured with this chart range from 3.5 to 56 lines/mm.

new developments and ideas follow so fast upon one another that it is impossible at this time to state unequivocally just what trpe of test chart is the best. Despite these circumstances, it was deemed advisable to prepare a new test chart that incorporated at least some of the adrances in knowledge and experience gained in the past 12 years.

\section{NBS Resolution Test Chart of $\mathbf{1 9 5 2}$}

\subsection{Description}

In the design of this test chart, sereral features not present in the older chart are included. All patterns have the same line count, namely, three to each group. Two series of test patterns are included, the spacings in the line patterns of a given group differing from those of the adjacent group so that their ratio is approximately $\sqrt[2]{2}$. However, in order to have the advantage of smaller intervals between steps, the spacings in the initial patterns of one series differ, correspondingly by the $\sqrt[4]{2}$ from those of the other series. Consequently, considered as a whole, the range of values provided by this chart proceed by the fourth root of 2. Perhaps the most striking feature of the new chart is the relatively great length of the lines forming the patterns. This has been done for two reasons. First, the ratio of length to width of line is sufficiently great that the visual resolving power as read will not be subject to rariations arising from end effects and the images will continue to look like lines down to the limit of resolution. Second, many laboratories are now equipped with microdensitometers, and it is desirable to have the 


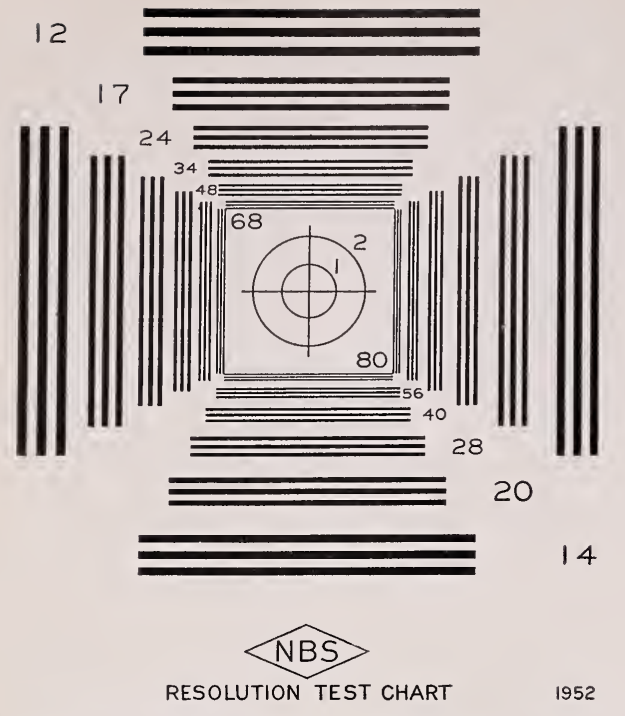

FIGURE 2. High-contrast resolution test chart.

The ratio of the line spacings in adjacent groups is equal to $\sqrt{2}$; however, the ratio of the line spacings of corresponding opposite patterns is $\sqrt[4]{2}$. Consequently when this chart is photographed at the standard distance of $26 f$, the values of resolving power than can be measured range from 12 to 80 lines $/ \mathrm{mm}$ in a geometric series proceeding by $\sqrt[4]{2}$.

lines sufficiently long to permit the negative images at $25 \times$ reduction to be scanned in such instruments without the necessity of so far reducing the length of the scanning slit that the loss of sensitivity of the instrument and effects of granularity of the emulsion impair the validity of measurement. In addition, the line patterns are so arranged in the chart that the negative images of all patterns can be scanned with only two settings of the test negative in the recording microdensitometer.

If, however, shorter lines are preferred, it is possible to obtain them by masking the lines on the present chart. The standard Air Force chart, for example, is of high contrast and consists of 3 lines and 2 spaces, the lines being 5 times as long as wide, thus forming a square pattern. Several such patterns for each frequency can be formed by blocking, or masking, out portions of the lines on the high-contrast chart.

In general, the resolving-power test with the black-and-white chart is adequate for determining the probable performance of a lens. However, it is well known that a single measure of resolving power at any one contrast does not completely characterize the performance of a lens. This is particularly the case if it is a general-purpose lens that is to be used for a variety of photographic purposes. Accordingly, the new charts accompanying this Circular are finished in two contrasts. Contrast, as used in this sense, is a measure of the relative brightness of the light and dark lines on the target. In photographic work it is convenient to use the difference in photographic density between light and dark areas as a measure of con-

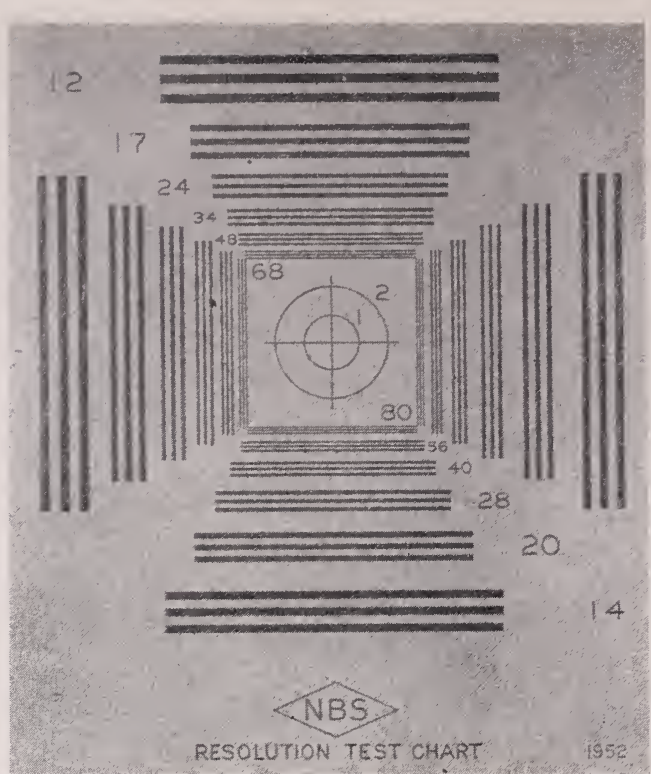

FIgURE 3. Low-contrast resolution test chart.

The metrical characteristics of this chart are identical with those of the high contrast chart shown in figure 2 . The contrast (ratio of reflection densities) between the gray ink of the lines and the gray background is approximately 0.20 . The contrast between lines and spaces in this target is more nearly like that in natural objects than is that in the high-contrast target.

trast. The density scale is logarithmic, and a relative brightness of light to dark of 10 to 1 is simply a contrast of 1.00. The ordinary black-and-white target, while frequently spoken of as a high-contrast target, actually has a contrast of less than 2.00 .

The test charts are shown in figures 2 and 3. Figure 2 is the high-contrast chart and consists of black lines on a white background. The contrast between the black-and-white lines on the actual test chart is approximately 1.4. Figure 3 is the low-contrast chart. The pattern is identical with that of the high-contrast chart. The low contrast is obtained by printing the lines with gray ink on gray paper. The approximate contrast between the lines and background is 0.20 .

\subsection{Metrical Characteristics}

The series of numbers along the diagonals ranging from 14 to 80 and 12 to 68 give the number of lines per millimeter on the negative when this chart, as reproduced, is photographed at a $25 \times$ reduction. 'Thus the number 14 refers to both the outer vertical 3-line group on the right and to the horizontal 3-line group at the bottom of the figure, whereas the number 12 refers to both the outer vertical 3-line group on the left and to the horizontal 3-line group at the top of the figure. The spacings of all groups are given in table 1 . These are the spacings specified in the initial design. The actual measured values may differ in some cases by as much as 1 percent from these design values. 
TABLE 1. Specified dimensions of patterns on NBS test chart

\begin{tabular}{|c|c|c|c|c|}
\hline $\begin{array}{l}\text { Pattern } \\
\text { number }\end{array}$ & $\begin{array}{l}\text { Width of } \\
\text { single black } \\
\text { or white } \\
\text { line }\end{array}$ & $\begin{array}{l}\text { Width of } \\
\text { 3-line } \\
\text { pattern }\end{array}$ & $\begin{array}{l}\text { Width of } \\
\text { space be- } \\
\text { tween } \\
\text { patterns }\end{array}$ & $\begin{array}{l}\text { Length of } \\
\text { lines }\end{array}$ \\
\hline So & $\begin{array}{l}m m \\
0.156\end{array}$ & $\begin{array}{l}m m \\
0.7 \$ 1\end{array}$ & \multirow{6}{*}{$\begin{array}{l}m m \\
0.781 \\
1.116 \\
1.562 \\
2.232 \\
3.125\end{array}$} & $\begin{array}{c}m m \\
18.0\end{array}$ \\
\hline 56 & .223 & 1. 116 & & 19. 6 \\
\hline 40 & .312 & 1. 562 & & 21.9 \\
\hline 28 & .446 & 2. 232 & & 25.1 \\
\hline 20 & .625 & 3.125 & & 29.6 \\
\hline 14 & .893 & 4. 464 & & 36.0 \\
\hline 68 & 0.184 & 0.919 & \multirow{6}{*}{$\begin{array}{r}0.582 \\
.825 \\
1.164 \\
1.649 \\
2.328\end{array}$} & 18.0 \\
\hline 48 & .260 & 1. 302 & & 19. ti \\
\hline 34 & .368 & 1.838 & & 21.9 \\
\hline 24 & .521 & 2. 604 & & 25.1 \\
\hline 17 & .735 & 3.676 & & 29.6 \\
\hline 12 & 1. 042 & 5. 208 & & 36.0 \\
\hline
\end{tabular}

For each pattern there are 2 groups of lines, 1 vertical and 1 horizontal. For most lenses it will be found that the resolving power at points not near the center of the negative is noticeably different for lines of the same spacing when the lines are oriented differently in the field. A consideration of the symmetry present at such a point indicates that the greatest and least resolving powers will be found for patterns of lines directed toward the center of the negative and at right angles to this direction, although one cannot say in advance which of the directions will correspond to the greater resolving power. If several test charts are arranged in a horizontal row for photographing at such a height that the line of images passes through the center of the negative, the horizontal lines will be directed toward the center of the field and are accordingly designated radial. The vertical lines are designated tangential. These terms will be used to designate the two different resolving powers for lines in the two characteristic direc tions. If these two resolving powers have different values at a point, it indicates the presence of coma $^{3}$ or astigmatism.

\subsection{Range of Chart at the Standard Distance}

The chart has been designed for use at a $25 X$ reduction which is obtained by placing the target 26 focal lengths in front of the lens being tested. Under these conditions, the range of values of the resolving power that can be directly read

\footnotetext{
${ }^{3}$ Coma and astigmatism are optical aberrations, which do not affect the images of axial points of a well-constructed lens but may be present in the images of points not lying on the axis of the lens. If coma is present, the image of a point will have a blurred extension extending toward or from the center of of a point will have a blurred extension extending toward or from the center of
the field. If astigmatism is present, the image of a point cannot be focused the field. If astigmatism is present, the image of a point cannot be focused
into a sharply defined point image, but, for one setting of the lens, it will be represented by a relatively sharp line segment lying along a radius passing through the center of the field, whereas for a second position, the image will be a relatirely well-defined line segment perpendicular to the radius.
}

from the images on the test negative is from 12 to 80 lines $/ \mathrm{mm}$. In the direction of finer patterns, the range of this test chart has been extended to 80 lines $/ \mathrm{mm}$ as compared with the maximum of 56 lines $/ \mathrm{mm}$ provided by the chart that accompanied Circular 428.

However, the patterns covering the range of resolving power from 3.5 to 10 lines $/ \mathrm{mm}$ that were present on the former test chart in Circular 428 when used at a $25 \times$ reduction are not present on this chart in the form of 3 -line patterns. These patterns were omitted to conserve space, as it would not be possible to include these patterns and still provide 6 charts on a single slip-in sheet. In addition, the prospective user is seldom interested in testing lenses with high-contrast targets where the resolving power falls below 12 lines $/ \mathrm{mm}$.

However, if desired, it is possible to use this chart to determine resolving power under 12 lines $/ \mathrm{mm}$. An approximate method is to treat each 3-line pattern as a single line (when the resolving power is under 12 lines/mm, the 3-line pattern will appear to be single lines in the image). When this is true, the successive 3-line patterns and intervening spaces can themselves be regarded as a resolving-power chart, and a good approximation of the actual value can be obtained from the manner in which the 3-line patterns and spaces merge. Accordingly, the resolving-power chart when used at $25 \times$ reduction provides a series of values of resolving power ranging from 3.5 to 14 lines $/ \mathrm{mm}$, preceding in steps of $\sqrt[2]{2}$. The actual values are shown in table 2 . It must be remembered that the values determined in this way are less accurate than when used for the normal range of 12 to 80 lines $/ \mathrm{mm}$. In fact, the error may be as high as 10 percent.

TABLE 2. Talues of the resolving power at $25 \times$ reduction when the space between specified 3-line patterns is still defined

\begin{tabular}{|c|c|}
\hline $\begin{array}{c}\text { Pattern } \\
\text { numbers }\end{array}$ & $\begin{array}{c}\text { Resolving } \\
\text { power }\end{array}$ \\
\hline $\begin{array}{l}80 \text { to } 56 \\
68 \text { to } 48 \\
56 \text { to } 40 \\
48 \text { to } 34 \\
40 \text { to } 28 \\
34 \text { to } 24 \\
28 \text { to } 20 \\
24 \text { to } 17 \\
20 \text { to } 14 \\
17 \text { to } 12\end{array}$ & $\begin{array}{c}\text { Lines } / \mathrm{mm} \\
\begin{array}{c}14 \\
10 \\
7 \\
5 \\
3.5\end{array}\end{array}$ \\
\hline
\end{tabular}

\subsection{Methods of Extending Chart Range}

To determine the resolving power for ranges not present in the target at $25 \times$ reduction, 2 courses are open to the user. The simplest course is to change the reduction ratio by altering the distance between the lens and the test chart. The other course is to change the size of the target by appropriate photographic procedures. 
(a) Change of Lens To Target Distance

The lines per millimeter marked on the chart are correct only when tests are conducted at the standard distances of $26 \mathrm{f}$. When tests are performed at other distances, the indicated values are corrected by use of the relation

$$
\text { Resolving power (lines } / \mathrm{mm})=(M / 25) N \text {, }
$$

where $M$ is the ratio of object to image size, and $N$ is the number in the chart associated with each pattern. For any value of the reduction ratio, $M$, the distance, $D$, the test chart should be placed in front of the front nodal point of the lens is given by the expression

$$
D=(M+1) f
$$

where $f$ is the equivalent focal length of the lens under test. (This distance is sufficiently well approximated by measuring from the front surface of the lens to the target for values of $M$ greater than 10 for the usual type of camera lens.) For convenience, the values of the resolving power associated with each pattern for a series of values of $M$ and $D$ are listed. It must be remembered that when using these test charts to determine resolving power at finite distances, the image plane of the lens does not coincide with the focal plane, which is the position occupied by the image plane when the camera is focused for parallel light. The distance, $d$, separating the image plane at reduction ratio $M$ from the focal plane is given by the expression

$$
d=f / M \text {. }
$$

For convenience, table 3 lists the number of lines per millimeter in the image plane corresponding to the indicated values for several values of the reduction ratio $M$.

\begin{tabular}{|c|c|c|c|c|c|}
\hline$M=-.-$ & 1 & 12.5 & 25 & 50 & 100 \\
\hline$D=\ldots$ & $2 f$ & $13.5 f$ & $26 f$ & $51 f$ & $101 f$ \\
\hline $\begin{array}{l}\text { Pattern } \\
\text { number }\end{array}$ & \multicolumn{5}{|c|}{ Resolving power in lines $/ \mathrm{mm}$} \\
\hline $\begin{array}{l}80 \\
56 \\
40 \\
28 \\
20 \\
14\end{array}$ & $\begin{array}{r}3.20 \\
2.24 \\
1.60 \\
1.12 \\
0.80 \\
.56\end{array}$ & $\begin{array}{r}40 \\
28 \\
20 \\
14 \\
10 \\
7\end{array}$ & $\begin{array}{l}80 \\
56 \\
40 \\
28 \\
20 \\
14\end{array}$ & $\begin{array}{r}160 \\
112 \\
80 \\
56 \\
40 \\
28\end{array}$ & $\begin{array}{r}320 \\
224 \\
160 \\
112 \\
80 \\
56\end{array}$ \\
\hline $\begin{array}{l}68 \\
48 \\
34 \\
24 \\
17 \\
12\end{array}$ & $\begin{array}{r}2.72 \\
1.92 \\
1.36 \\
0.96 \\
.68 \\
.48\end{array}$ & $\begin{array}{c}34 \\
24 \\
17 \\
12 \\
8.5 \\
6\end{array}$ & $\begin{array}{l}68 \\
48 \\
34 \\
24 \\
17 \\
12\end{array}$ & $\begin{array}{r}136 \\
96 \\
68 \\
48 \\
34 \\
24\end{array}$ & $\begin{array}{r}272 \\
192 \\
136 \\
96 \\
68 \\
48\end{array}$ \\
\hline
\end{tabular}

TABLE 3. Number of lines per millimeter in the image plane for several values of the reduction ratio $M$

\section{(b) Change of chart size by photographic means}

In cases where space does not permit the use of long ranges, it is advantageous to change the size of the test chart itself by copying to the desired size and then using the resulting negative as a transparency or printing it on glossy paper. If an enlarged copy is desired, it is wise to use a moderately long focus copying lens, because the imagery in the center of the field is usually superior. It is suggested that the half-angle subtended at the lens by the center and corner of the test chart be kept under $15^{\circ}$. While greater half-angles are allowable, one is less likely to encounter noticeable distortion and loss of definition when the halfangle is kept small. The approximate focal length of the lens can be computed in a simple manner. The distance from corner-to-corner of a single test chart is approximately $100 \mathrm{~mm}$. The equation

$$
f=\frac{m R}{m+1} \cot \beta
$$

can be used to determine the value of the focal length $f$, where $R$ is the distance from center-tocorner of the chart, $m$ is the desired magnification, and $\beta$ is the half-angle subtended at the lens by $R$. For $R=50 \mathrm{~mm}, m=4$, and $\beta=15^{\circ}$, the value of $f$ is $149 \mathrm{~mm}$, or approximately 6 inches. If charts enlarged by amount $m$ are used in testing lenses at a $25 \times$ reduction, the range of the chart is changed by $1 / m$. Thus for $m=4$, the range of the chart will run from 3 to 20 instead of from 12 to 80 lines $/ \mathrm{mm}$. In making enlargements, it is desirable that a high-contrast emulsion be used to ensure clear whites and high-density black lines. Any good process emulsion will serve for enlarging the high-contrast target. For the low-contrast target, it will perhaps be preferable to use an ordinary panchromatic emulsion.

The case for $m=4$ is especially interesting for this resolution chart. If the chart is enlarged four times, it will be of such a size that the original chart may be inserted in the central square, where the circle charts are located. If the number on the negative used in the enlargement is opaqued, then a new series of numbers can be lettered on the enlarged print of the chart running from 3 to 20 . Then when the original chart is placed in the central square on the enlarged, one will have a new chart with the range extending from 3 to 80 lines $/ \mathrm{mm}$. A chart of this type is illustrated in figure 4. It is true that certain patterns will be repeated on the composite chart, namely, 12,14 , 17 , and 20 , but this is certainly no disadvantage. This process of expanding the range of the chart can be extended in both directions. For a reduction of the original target in the ratio 4 to 1 , the range of the reduced target is from 48 to 320 lines $/ \mathrm{mm}$. If this is placed on the center of the expanded composite target, the resulting target has a range from 3 to 320 lines $/ \mathrm{mm}$ when used at a distance of $26 f$. 


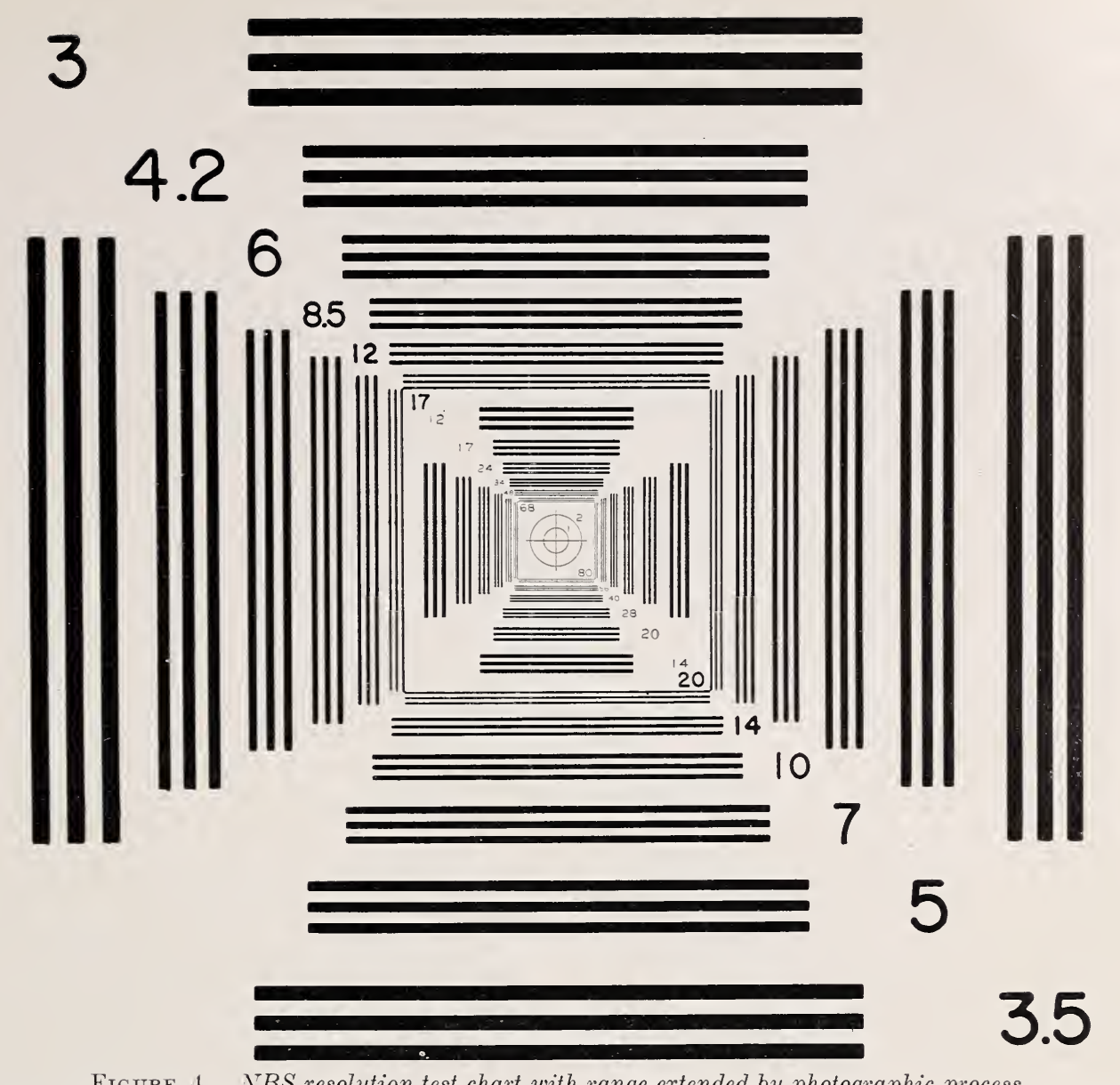

FIGURE 4. NBS resolution test chart with range extended by photographic process.

This chart is a composite formed by superimposing the high-contrast chart upon an enlarged copy of the master chart. The ratio of magnification is 4 . The range of the composite chart is from 3 to 80 lines $/ \mathrm{mm}$ as compared to the original range of 12 to 80 lines $/ \mathrm{mm}$.

It may be desirable at times to produce small replicas of the chart in the form of transparencies for use as reticles or for studying the resolution characteristics of microscopic systems. This can be done quite simply by photographing the chart to the desired size on a high-contrast fine-grain emulsion, such as Eastman 548GH Spectroscopic Plate or 649GH Spectroscopic Plate. With these emulsions it is possible to photograph to a very fine scale with minimal change in ratio of line widths. A Micro Tessar lens or a microscope objective is best suited for this trpe of work. It must be borne in mind that the lens aperture must be great enough to permit the fine lines of the target to be resolved in the negative. Under these conditions a sufficiently good approximation to the ultimate resolving power of a lens is given by the relation

$$
\text { Resolving power (lines } / \mathrm{mm})=\frac{1426}{f \text {-number }}
$$

Thus for an $f / 4.5$ lens operating at full aperture, one cannot expect to image lines finer than 317 lines $/ \mathrm{mm}$. One of the authors has produced reti- cles with the number of lines per millimeter in the finest pattern resolved as high as 400 lines $/ \mathrm{mm}$ with an $f / 2.8$ lens, and it is probable that still finer patterns can be photographed without undue effort. In photographing at high reductions, one must be quite meticulous in achieving the best possible focus. The depth of focus in the image plane for a given lens is a function of the $f$-number and the number of lines to be resolved, thus

Depth of focus $=\frac{4 \times f \text {-number }}{\text { resolving power (lines } / \mathrm{mm})}$.

With this equation the depth of focus is measured in millimeters. The above expression is meaningful only if the resolving power does not exceed the maximum possible for the given $f$-number. For example, for the $f / 4.5$ lens with a maximum resolving power of 317 lines $/ \mathrm{mm}$, this resolving power can only be obtained for a depth of focus of $0.056 \mathrm{~mm}$. In the case of the $f / 2.8$ lens, the 400-line pattern was resolvable for a depth of focus of $0.028 \mathrm{~mm}$. The ultimate resolving power of this $f / 2.8$ lens would be 509 lines $/ \mathrm{mm}$, which would be obtainable for a depth of focus of $0.022 \mathrm{~mm}$. 


\subsection{Method of Changing Length of Line Patterns}

The use of long lines departs from most currently accepted practice for the formation of resolvingpower charts. However, it was, necessary in order to obtain patterns on the negative capable of being scamned by a recording microdensitometer. It is reasonable to believe that the results obtained by visual analysis of resolving-power tests made with these long-line patterns will be essentially the same as those obtained with short-line patterns.

Before this belief is generally accepted, it is probable that some experimenters will wish to make studies of the resolving-power characteristics of lenses with both types of target under comparable conditions. The present chart can be readily modified to make such studies. To do this, it is only necessary to mask the lines in an appropriate manner on the present chart.

The standard Air Force chart is a short-line chart of high contrast and consists of 3 lines and 2 spaces. The lines are five times as long as wide, thus forming a square pattern. Several such patterns can be formed by blocking, or masking, out portions of the lines on the long-line highcontrast chart described in this Circular.

An example of this type of chart modification is shown in figure 5 . This chart was prepared by making an enlarged copy of the original chart on a glass negative. The unwanted portions of the long-line patterns were opaqued. Copies of this negative of the desired size are then printed. The resulting chart then contains both types of line pattern, thus making easy a comparison of

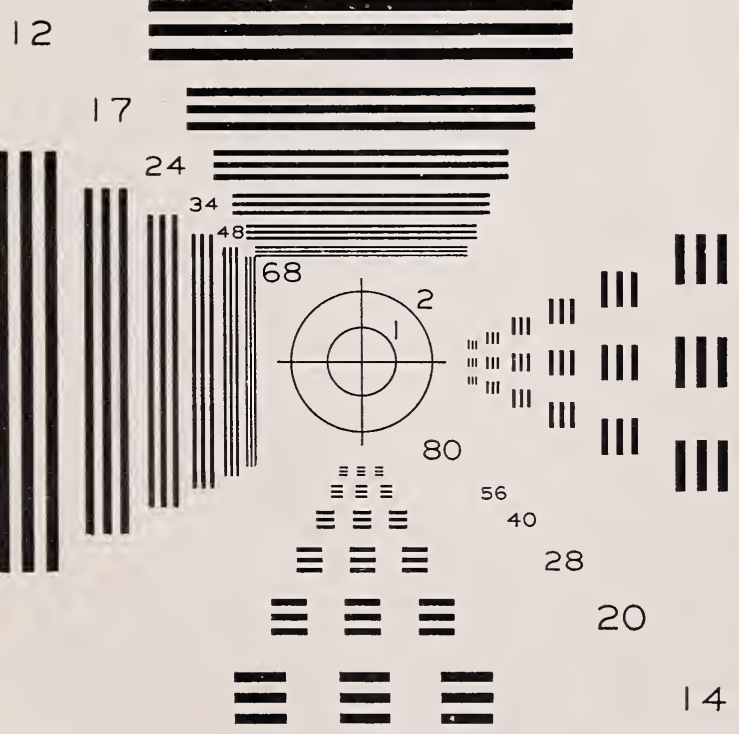

FiguRE 5. Short-line target derived from long-line target.

This chart is formed by appropriate masking out portions of the long line pattern on two sides of the target. This modification may be used in comparison studies of short-line and long-line targets. results obtained with long-line and short-line patterns. Use of a chart of this type is especially advantageous in comparison studies, as there can be no question of the prevalence of comparable conditions.

If one does not wish to use the direct copy as a reticle or test chart, the reverse pattern can easily be obtained by contact printing. This may be done fairly readily with the aid of a small distant light source, which minimizes the lack of sharpness resulting from imperfect contact between the negative and the emulsion surface. A high-pressure mercury arc serves very well for this purpose as it is small, and its high intensity helps to avoid long exposure times.

In making copies of this kind it is difficult to maintain the same contrast for all patterns. When the fine lines are exposed sufficiently to be well defined, the coarse patterns are likely to be overexposed. This effect can be minimized by appropriate dodging. It is also helpful to place the emulsion surface in the image plane of maximum contrast instead of in the image plane of maximum resolving power, provided the image plane of maximum contrast will resolve the finest pattern.

\section{Details of Camera Test}

\subsection{Arrangement of Charts}

The resolving power is not the same across the entire negative but is usually greatest at the center and decreases along any radius. It is commonly considered that a lens is perfectly symmetrical about its axis, and that the performance of the lens will accordingly be identical throughout a given zone concentric to the center of the field.

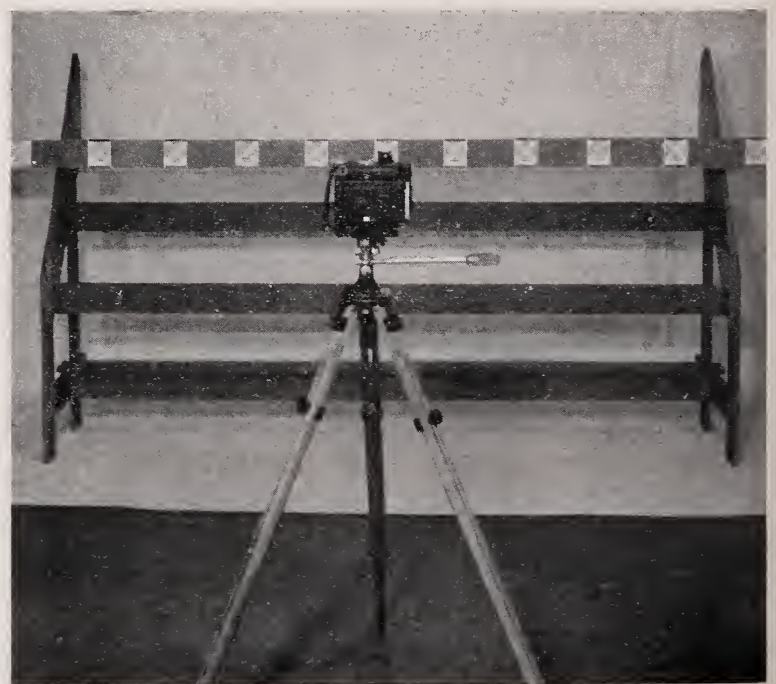

Figure 6. Arrangement of camera and charts for test.

The charts are conveniently mounted on a 1- by 4-inch board. The spacings of the individual charts are such that the angle between successive charts, measured at the camera lens, is 5 degrees. 
A perfectly symmetrical lens is probably nerer realized because of the unavoidable errors in workmanship, but, except for the most exacting purposes, it is satisfactory to treat the field as symmetrical. Accordingly, if the resolving power is measured at selected points along a given diameter, the ralues obtained may be considered representative for the entire picture area. It is conrenient to measure the resolving power at 5-degree intervals with the charts arranged in a horizontal row, as shown in figure 6 . Figure 7 is a schematic drawing showing the spacing of the charts and the position of the camera with respect to the row of charts. The distances are given in terms of $f$, so each coefficient must be multiplied by the focal length of the lens under test to determine the required spacing for 5-degree intervals. For convenience, table 4 lists the value of the spacings reckoned from the zero position for values of $\beta$ up to 45 degrees by 5 -degree steps for 4 values of the focal length. The distance separating lens and zero chart is also given for the same 4 values of focal length.

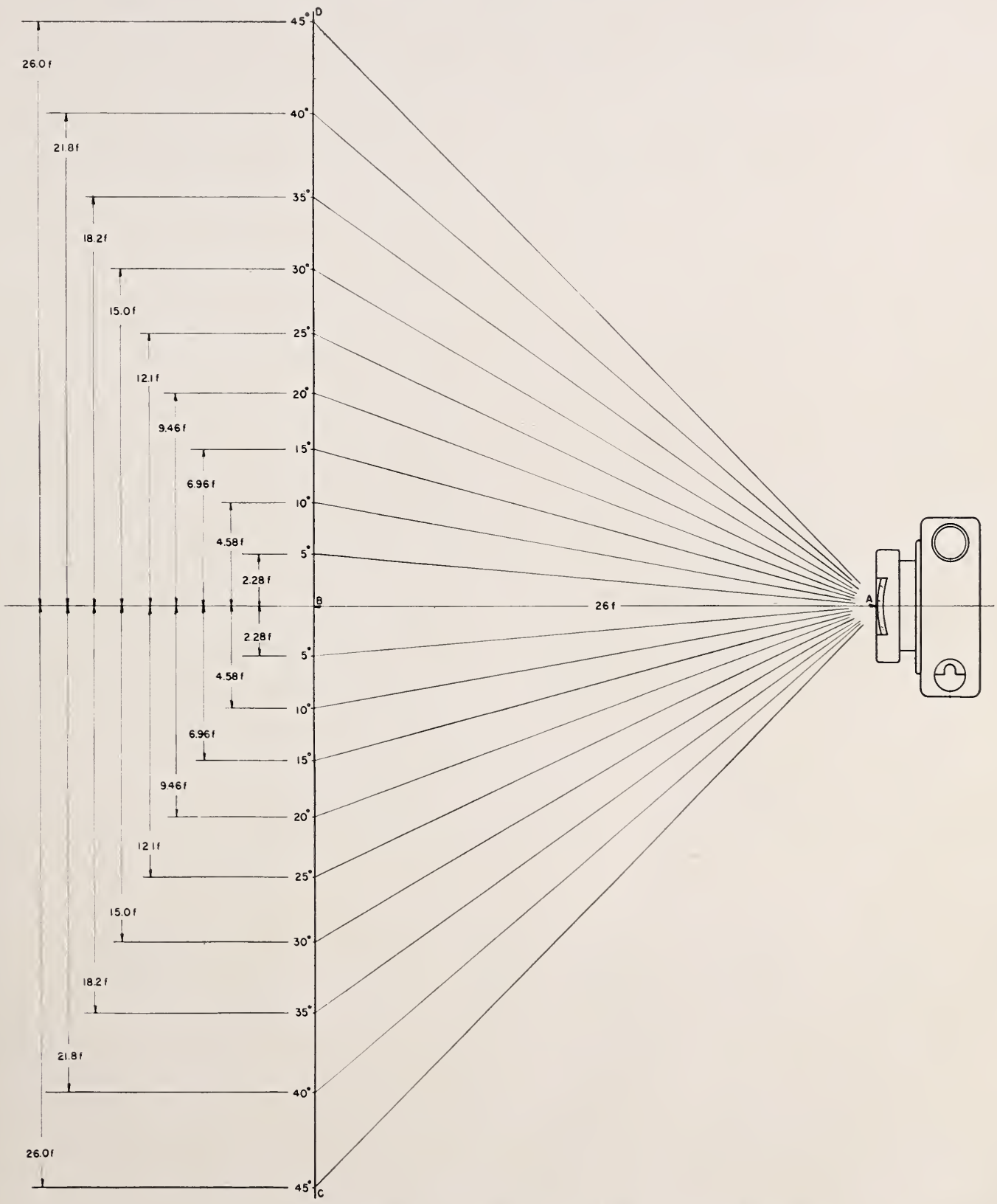

Figure 7. Plan view of arrangement of camera and charts for test.

This is a plan view of the arrangement of charts and camera shown in fig. 5. The distances are given in terms of $f$, the focal length of the camera lens. If the distances $A C$ and $A D$ are made equal, the camera is located on the perpeudicular bisector of length $C D$ and is, therefore, directly opposite the central chart. 


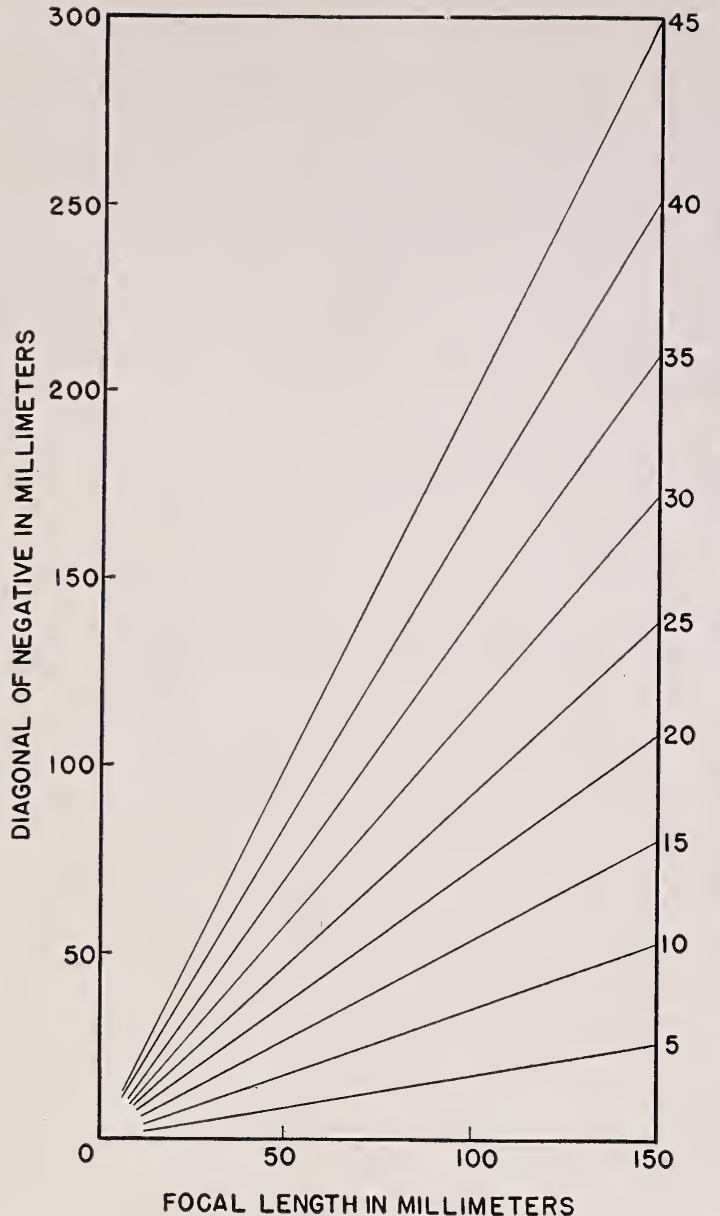

FIGURE 8. Length of negative diagonal as a function of the half-angle of view, $\beta$, for several values of the focal length.

This graph can be used to evaluate the half-angle of view for a given camera when the focal length of the lens and the length of the negative diagonal is known.
TABLE 4. Distance $(f \tan \beta)$ normal to lens axis, to chart located at angle $\beta$ from central target and distance along lens axis from front of lens to central target for several values of the focal length, $f$

\begin{tabular}{|c|c|c|c|c|c|}
\hline \multicolumn{2}{|c|}{$f($ in $\mathrm{mm})$} & 25 & 50 & 75 & 100 \\
\hline \multicolumn{2}{|c|}{$26 f($ in $\mathrm{mm})$} & 650 & 1,300 & 1,950 & 2,600 \\
\hline$\beta$ & $\tan \beta$ & \multicolumn{4}{|c|}{$26 f \tan \beta$} \\
\hline Degrees & & $m m$ & $m m$ & $m m$ & $m m$ \\
\hline $\begin{array}{l}0 \\
5\end{array}$ & $\begin{array}{l}0.0000 \\
.0875\end{array}$ & $\begin{array}{r}0 \\
57\end{array}$ & $\begin{array}{r}0 \\
14\end{array}$ & 0 & 0 \\
\hline 10 & .176 & 115 & 229 & 344 & 458 \\
\hline 15 & .268 & 174 & 348 & 522 & 696 \\
\hline 20 & .364 & 237 & 473 & 710 & 946 \\
\hline 25 & .466 & 303 & 606 & 909 & 1,212 \\
\hline 30 & .577 & 375 & 751 & 1,126 & 1,501 \\
\hline 35 & .700 & 455 & 910 & 1,365 & 1,820 \\
\hline 40 & .839 & 545 & 1,091 & 1,636 & 2,182 \\
\hline 45 & 1.000 & 650 & 1,300 & 1,950 & 2,600 \\
\hline
\end{tabular}

The larger values of the angles are given to provide complete data for the testing of lenses of extremely wide angle. The field of a lens of $50-\mathrm{mm}$ focal length used with a $35-\mathrm{mm}$ film $(24 \times 36 \mathrm{~mm}$ negative) extends only 23.4 degrees when measured from the center to the extreme corner. The magnitude of the angle separating center and corner of the negative can be determined approximately with the aid of figure 8 . The length of the diagonal of the negative is measured and the nominal focal length of the lens is noted. With these values as ordinate and abscissa, respectively, a point is located on the graph. If the point falls on one of the sloping lines, the value of the angle is given directly. If the point falls between two lines, the value of the angle can be determined sufficiently closely by interpolation. The angle so determined is one-half the total angle of view of the camera.

\subsection{Camera Support}

The camera support should be sufficiently rigid that no vibration effects will be likely to impair the quality of definition. If the camera is attached to the tripod in the usual manner and leveled, the row of images will extend across the photograph, as indicated in figure 9 , and the resolving power

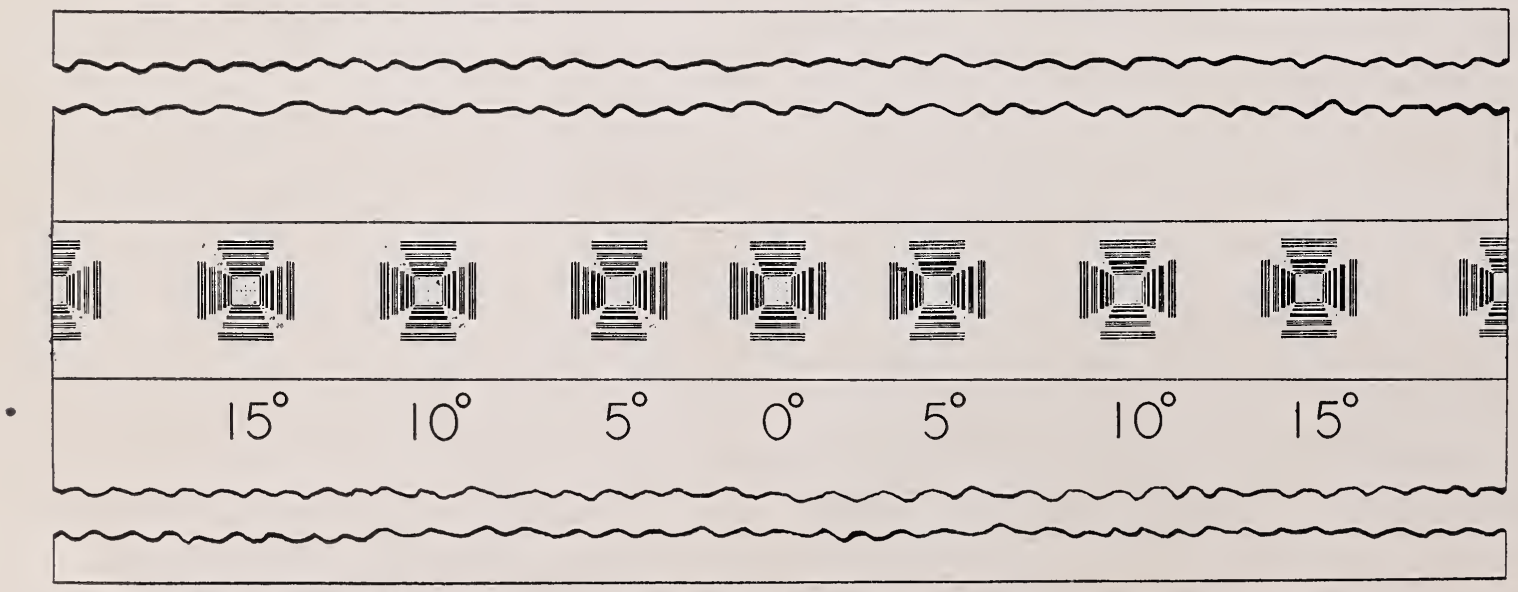

FIGURE 9. Diagram showing position of test patterns in the image area for one orientation of the camera.

For this arrangement, the camera is mounted on the tripod, so that the longer axis of the image area is horizontal. Diagram has been foreshortened vertically. 
near the corners will not be determined. If a tilting-head tripod is used with the camera so mounted that the camera may be rotated about an axis parallel to the lens axis, the camera can then be adjusted so that the recorded images on the photograph will fall along a diagonal, as indicated in figure 10 . In this manner, the resolving power can be determined in the corner of the field. This same result can be obtained by keeping the camera leveled on the tripod and rotating the board, upon which the charts are mounted, through the proper angle. This latter course is usually, however, less conrenient.

\subsection{Use of Multiple Rows of Charts ${ }^{4}$}

It will be readily understood that the correct resolving power for a lens will not be obtained unless it is correctly focused. If many lenses are to be tested, it is adrantageous to have the arrangement of charts shown in figure 11, as it largely eliminates the making of several exposures in order to make sure that good focus is obtained. There are five rows of charts, placed one above the other, all at different distances from the lens, but not far from the horizontal plane containing the camera axis. The lens to be tested is placed at a perpendicular distance, $26 f$, from the center of the middle row, and the camera is focused upon the central chart of this row. If the focus is correct, the central row of charts will be the sharpest on the resulting negative. If an error has been made in the setting, one of the nearer or farther rows of images will be sharper than the central one, and if the error in focusing is not too great, one row will be in good focus, and the resolving powers can be read from it without making an additional exposure. If the five rows of charts are used as shown, they can be spaced in the direction of the line of sight, so that the planes of best imagery of the different rows, measured in a direction perpendicular to the film, will be spaced $0.1 \mathrm{~mm}$. The proper spacing of the rows measured from the central row is given in table 5 for $d=+0.2,+0.1,0-0.1$, and -0.2 .

In setting up the charts and camera, care must be taken that the distances are exact and that the axis of the camera is perpendicular to the row of charts, with the lens opposite the central target. For a camera of short focal length, it is convenient to do the work indoors. The charts and the camera can then be adjusted to the same height by measuring upward from the floor. The distance from the camera to the central chart should

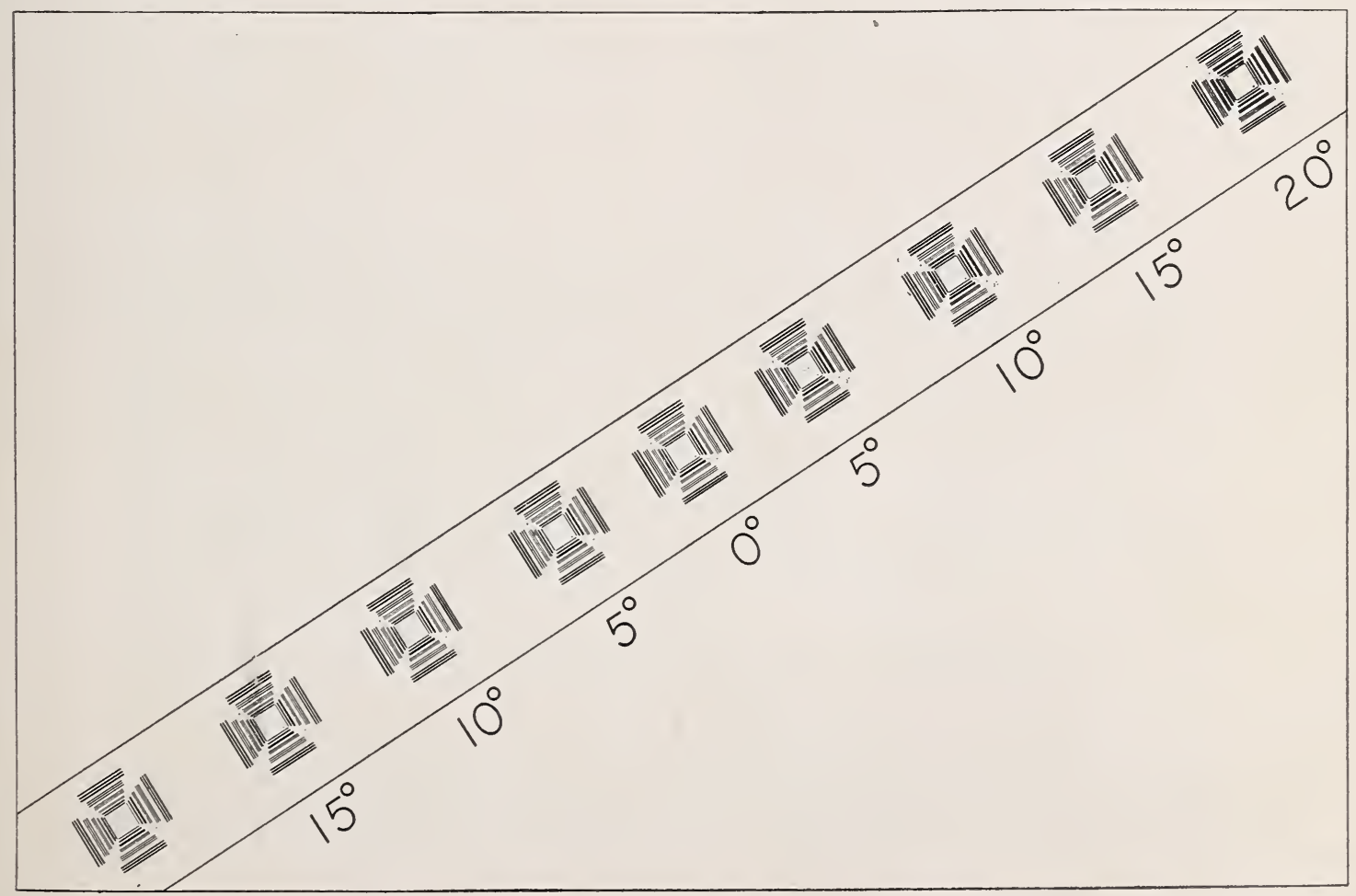

FIGURE 10. Diagram showing position of test patterns when test is extended to the corners of the image area.

For this arrangement, the camera is tilted in a manner similar to that shown in figure 11. This arrangement gives a more complete test of the lens than that illustrated in figure 9 .

${ }^{4}$ Additional charts, in sets of 12 (6 high contrast (1 page) and 6 low contrast ( 1 page) may be obtained from the Superintendent of Documents, Washington, D. C. When ordering, they should be referred to as "Charts for testing lens resolution. Supplement to N BS Circular 533." 
TABLE 5. Talues of the distances $\delta D$, measured from a plane distant $26 f$ from the lens, necessary to displace the image plane by anounts $\delta$ d.

\begin{tabular}{|c|c|c|c|c|}
\hline \multirow{3}{*}{$\delta d$} & \multicolumn{4}{|c|}{$f$ in $\mathrm{mm}$} \\
\hline & 25 & 50 & 75 & 1000 \\
\hline & \multicolumn{4}{|c|}{$\delta I I$} \\
\hline $\begin{array}{r}m m \\
+0.5 \\
.4 \\
.3 \\
.2 \\
.1 \\
0 \\
-.1 \\
-.2 \\
-.3 \\
-.4 \\
-.5\end{array}$ & $\begin{array}{c}m m \\
-20 \mathrm{~s} .8 \\
-17.6 \\
-144.2 \\
-104.2 \\
-56.8 \\
0 \\
69.4 \\
156.2 \\
267.9 \\
416.7 \\
625.0\end{array}$ & $\begin{array}{c}m m \\
-250.0 \\
-208.3 \\
-163.0 \\
-113.6 \\
-59.5 \\
0 \\
65.8 \\
138.9 \\
220.6 \\
312.5 \\
416.7\end{array}$ & $\begin{array}{r}m m \\
-267.9 \\
-220.6 \\
-170.4 \\
-117.2 \\
-60.5 \\
0 \\
64.7 \\
133.9 \\
208.3 \\
240.4 \\
375.0\end{array}$ & $\begin{array}{c}m m \\
-277.8 \\
-227.3 \\
-174.4 \\
-119.0 \\
-61.0 \\
0 \\
64.1 \\
131.6 \\
202.7 \\
277.8 \\
357.1\end{array}$ \\
\hline
\end{tabular}

be measured from the first principal point ${ }^{5}$ of the lens. In general, the location of this point will not be known, but it will be sufficiently accurate to measure from the front surface of the lens. It will be found most convenient to measure all horizontal distances on the floor and to use plumb bobs to properly locate the parts above the measured points. If plump bobs are not conveniently available, large screw eyes hung with the pointed ends downward are a satisfactory substitute. Four plumb bobs are desirable, one to locate the front surface of the lens, one to locate the center of the central chart, and one each at the corners of two outermost charts. The projections of these points are located at $A, B, C$, and $D$ on figure 7 . The distance $A B$ should be $26 f$.
In order to be sure that the camera is directly opposite the central target, $A C$ and $A D$ must be equal. This condition locates the camera on the perpendicular bisector of $C D$. With the camera over $A$, it must be so oriented by means of the view finder, or ground glass, that the central chart appears in the center of the photograph. If these adjustments are all accomplished as described, the camera will be directed squarely at the central chart.

If manv cameras are to be tested, it is convenient to lay off the distances on the floor and indicate the significant points by tacks. If plumb bobs are permanently attached to the strip that carries the charts and to the tripod, it is a simple matter to restore the correct adjustment by adjusting the plumb bobs over the tacks. A rack, such as is shown in figure 11, equipped with plumb bobs and used in this manner with a system of tacks indicating the positions for the commoner focal lengths will be found to be an especially convenient piece of testing equipment for photographic clubs, as it will enable each member to acquire for himself valuable and useful information about the performance of his lenses.

\section{(a) Determination of Focusing Error}

It sometimes happens that the unsatisfactory performance of a lens is a result arising from errors in the focusing scale or in the adjustment of the coupled rangefinder. Errors of this nature can be detected by photographing the test chart at various distances in front of the lens without

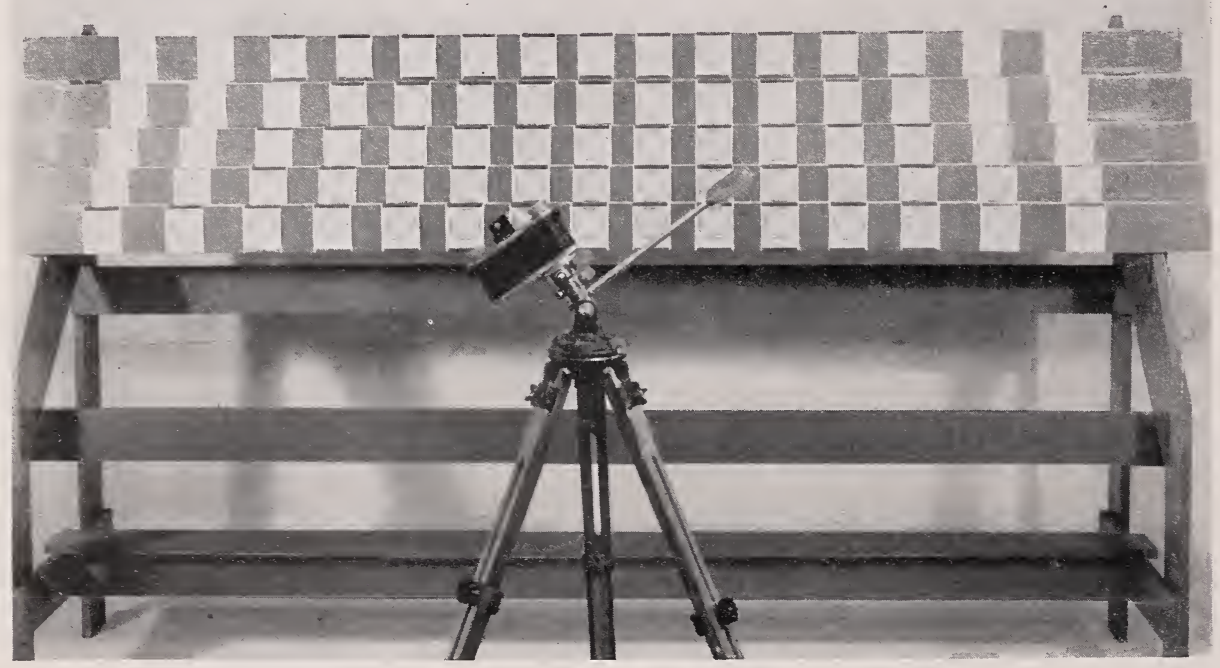

FIgURE 11. Test rack with multiple rows of charts.

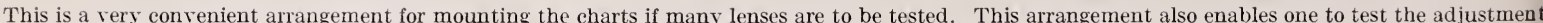
of a coupled range finder. The method of determining the proper separation of the rows of charts is given in section 8.3 .

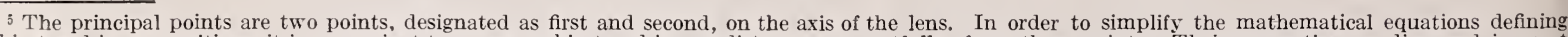

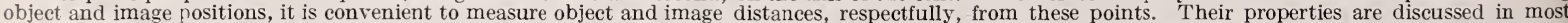
books on optics. See chapter 4 of "The Principles of Opties", by Hardy and Perrin (MeGraw-Hill Book Co., Inc., New York, N. Y.). 
changing the position of the lens with respect to the film plane during successive exposures or by a single exposure with several targets spaced at rarring distances from the lens. $\mathrm{B}_{r}$ a proper selection of distances and proper interpretation of the results, the direction and the approximate magnitude of the focusing error can be determined.

Let one target be set at $\left(M_{0}+1\right) f$ distance from the lens, where $M_{0}$ is the ratio of object to image size (in the usual case, $M_{0}=25$ ), and $f$ is the focal length of the lens in millimeters. Then

$$
\begin{aligned}
& D_{0}=\left(M_{0}+1\right) f \\
& d_{0}=\left(1+\frac{1}{M_{0}}\right) f
\end{aligned}
$$

where $D_{0}$ is the object distance, and $d_{0}$ is the image distance. Now let another target be placed at distance $D$ from the lens, then

$$
\begin{aligned}
& D=(M+1) f \\
& d=\left(1+\frac{1}{M}\right) f
\end{aligned}
$$

The difference in position of the image planes is then giren by the relation

$$
\delta d=\frac{f}{M}-\frac{f}{M_{0}}=f \frac{\left(M_{0}-M\right)}{\left(M_{0} M\right)}
$$

whence

$$
M=\frac{M_{0} f}{f+M_{0} \delta d}
$$

and the distance $\delta D$ of the second target from the first is given by the relation

$$
\delta D=D-D_{0}=-\frac{M_{0}^{2} f \delta d}{f+M_{0} \delta d} .
$$

For $\mathrm{M}_{0}=25$, the relations become

$$
\begin{aligned}
& \delta d=f\left(\frac{25-M}{25 M}\right), \\
& M=\frac{25 f}{f+25 \delta d},
\end{aligned}
$$

and

$$
\delta D=-\frac{625 f \delta d}{f+25 \delta d}
$$

It is convenient to so set the target distances that $\delta d$ ranges from +0.5 to $-0.5 \mathrm{~mm}$. For conrenience, table 5 lists values of $\delta D$ for this range of ralues of $\delta d$ for $t$ values of $f$. It must be remembered that these are distances measured from the plane distant $D_{0}=26 f$ from the lens. The varring ralues of $D$ will produce a rariation in $M$. so that the image of the targets will not be identical in size.
Table 6 gives the ralues of $M$ corresponding to the various values of $\delta D$ and $f$ for which the ralues of $\delta D$ are shown in table 5 . These values of $I I$ are necessarily approximate because the true position of the plane of best imagerr is not known. The values of $M$ are therefore computed on the assumption that the failure to compensate for change in image size by resetting the image plane is negligible for the small range involved. In the worst case, for the $25-\mathrm{mm}$ lens this effect can change $M$ by only 4 percent, and it is safe to assume that this error will usually be less than 1 percent.

These changes in $M$ are quite important because failure to appreciate this factor may result in erroneous conclusions regarding the condition of focus of the lens under test. The change in $M$ changes the scale in the chart, which is designed to be direct reading for $M=25$. Consequently, when used for a different ralue of $M$, the values of resolving power inscribed on the chart must be multiplied by $M / 25$, as listed in table 7 . to get the

\begin{tabular}{|c|c|c|c|c|}
\hline \multirow{3}{*}{$\delta d$} & \multicolumn{4}{|c|}{$f$ in $\mathrm{mm}$} \\
\hline & 25 & 50 & 75 & 100 \\
\hline & \multicolumn{4}{|c|}{$M$} \\
\hline$m m$ & & & & \\
\hline+0.5 & 16. 7 & 20.0 & 21.4 & $2 \% 2$ \\
\hline & 17.8 & 20.8 & 22.1 & 22.7 \\
\hline & 19. 2 & 21.7 & 22.7 & 23.3 \\
\hline & 20.5 & 22. 7 & 23.4 & 23. \\
\hline & 22.7 & 23.8 & 24.2 & 24.4 \\
\hline 0 & 25.0 & 24.0 & 25.0 & 25.0 \\
\hline-.1 & $2 \pi .8$ & 26.3 & 25.9 & 25.6 \\
\hline-.2 & 31.2 & 27.5 & 26.9 & 26.3 \\
\hline-.3 & 35.7 & 29.4 & $2 \overline{7} .8$ & 27.0 \\
\hline.$- t$ & 41. 7 & 31. 2 & 28.9 & $2 \pi$ \\
\hline-.5 & 50.0 & 33.3 & 30.0 & 28.6 \\
\hline
\end{tabular}
true ralues. The change in size between successive patterns on the chart is 1.1892 or 0.8409 . Therefore, if one were testing an $f / 4$ lens and had an indicated reading of 48 lines $/ \mathrm{mm}$ for $\delta=+.1$,

\begin{tabular}{|c|c|c|c|c|}
\hline$f$ in $\mathrm{mm}$ & 25 & 50 & 75 & 100 \\
\hline$\delta 1$ & \multicolumn{4}{|c|}{ M 25} \\
\hline $\begin{array}{r}m m \\
+0.5 \\
.4 \\
.3 \\
.2 \\
.1 \\
0 \\
-.1 \\
-.2 \\
-.3 \\
-.4 \\
-.5\end{array}$ & $\begin{array}{r}0.67 \\
.71 \\
.7 \\
.83 \\
.91 \\
1.00 \\
1.11 \\
1.25 \\
1.43 \\
1.67 \\
2.00\end{array}$ & $\begin{array}{r}0.80 \\
.83 \\
.87 \\
.91 \\
.95 \\
1.00 \\
1.05 \\
1.11 \\
1.18 \\
1.25 \\
1.33\end{array}$ & $\begin{array}{r}0.56 \\
.8 \\
.91 \\
.94 \\
.97 \\
1.00 \\
1.03 \\
1.07 \\
1.11 \\
1.15 \\
1.20\end{array}$ & $\begin{array}{r}0.84 \\
.91 \\
.93 \\
.95 \\
.94 \\
1.00 \\
1.02 \\
1.05 \\
1.05 \\
1.11 \\
1.14\end{array}$ \\
\hline
\end{tabular}
$\delta=0$, and $\delta=-.1$, he might assume that the focus was satisfactory. Howerer, on making the cor-

TABLE 6. T'alues of the reduction ratio $M$ for targets set at such distances from the lens that their proper focus would differ by amounts $\delta d$ from the image plane for $M_{0}=2.5$

TABLE 7 Talues of the factor $M, 25$ by which the indicated resolving power must be multiplied to obtain the true resolving power 
rections, the true resolving power would be 44,48 , and 53 lines $/ \mathrm{mm}$, which shows that the lens is out of focus by $-.1 \mathrm{~mm}$, and that the lens should be moved 0.1 nearer to the image plane to yield optimum results. Errors of this type are not likely to occur at the small $f$-numbers because of the small depth of focus. They are quite likely to occur at large $f$-numbers. 'For example, at $f / 11$, where the depth of focus is appreciable, failure to make the necessary corrections can result in marked errors. This is shown in table 8 . Here casual inspection of the indicated readings would lead to the belief that the position of best focus lies between the values of $\delta=+.2$ and +.1 , whereas when corrections are made the position of best focus is clearly at $\delta=-.2 \mathrm{~mm}$.

TABLE 8. Indicated and corrected values of the resolving power for a 25-mm lens capable of resolving 60 lines per millimeter tested at $\mathrm{f} / 11$ for several values of $\delta d$

\begin{tabular}{|c|c|c|}
\hline \multirow{2}{*}{$\delta d$} & \multicolumn{2}{|c|}{$\begin{array}{l}\text { Resolving power } \\
\text { (lines/mm) }\end{array}$} \\
\hline & Indicated & Corrected \\
\hline $\begin{array}{r}m m \\
0.4 \\
.3 \\
.2 \\
.1 \\
0 \\
-.1 \\
-.2 \\
-. .3 \\
-. .4 \\
-.5\end{array}$ & $\begin{array}{l}48 \\
56 \\
56 \\
56 \\
56 \\
48 \\
48 \\
40 \\
34 \\
28\end{array}$ & $\begin{array}{l}34 \\
43 \\
46 \\
51 \\
56 \\
53 \\
60 \\
57 \\
57 \\
56\end{array}$ \\
\hline
\end{tabular}

Fortunately, errors of this sort decrease with increased focal length and become almost nonexistent for values of $f$ greater than $100 \mathrm{~mm}$. It must be considered for the short-focal-length lenses when the test is made at $f$-numbers above f/5.6. It also must be guarded against when the emulsion used places an upper limit on the resolving power. For example, if the practical upper limit of the emulsion is 40 lines $/ \mathrm{mm}$, the depth of focus may be great enough to occasion difficulty. All of these difficulties can be avoided however by making the proper correction for the change in reduction ratio. An estimate of the probable depth of focus for a lens of a given $f$-number is given by the formula

\section{Depth of focus in $\mathrm{mm}=$}

$$
\frac{4 \times f \text {-number }}{\text { Resolving power in lines } / \mathrm{mm}} \text {. }
$$

\subsection{Illumination of Charts}

Satisfactory negatives cannot be obtained unless the charts are uniformly illuminated. If lenses of the shorter focal lengths, such as are used in miniature cameras, are to be tested, it is convenient to make the exposures indoors. Windows directly behind the camera are certain to produce unsatisfactory illumination because of specular reflection from the charts. In the usual home, a room is seldom found with the windows so arranged that none of the charts will reflect light directly into the lens with consequent overexposure of such charts. It is advisable to make the test at night or with shades drawn and to depend upon photoflood lights for the illumination. Two photoflood lights placed, one at either side, 3 or 4 feet in front of the plane of the charts (that is, toward the camera) and 4 or 5 feet beyond either end of the group of charts, will give satisfactory illumination. For lenses of longer focal length, the distance $26 f$ becomes so great that it is usually more convenient to make the exposure outdoors.

Frequently, one or more of the images are found to be overexposed as a result of light from the light sources being specularly reflected into the lens from the glossy surface of some of the charts. This can usually be prevented by careful adjustment of the light sources until all charts appear equally bright when viewed from the position occupied by the camera lens. Examination of the image in the view finder will frequently enable the experimenter to locate trouble of this kind before making the test exposures. This difficulty can be eliminated altogether if polarizing filters are placed over the light sources that illuminate the charts. A similar filter is used over the lens, and by proper adjustment the excessive light from the areas of specular reflection can be reduced to a point where it is no longer troublesome. Unless the polarizing filter is of excellent quality, however, the resolving power of the lens and filter may be less than that of the lens alone.

\subsection{Methods of Focusing}

\section{(a) Focusing by Means of Coupled Range Finder}

If the camera is equipped with a range finder coupled to the lens, it may be advisable in order to attain greater precision, to focus with the help of a low-power telescope, focused to view distant objects. A 3- or 4-power telescope can be held directly behind the range finder so that the light passes from the object through the range finder, then through the telescope, and then to the eye. With this arrangement, the images are magnified and their coincidence can be more exactly determined. If a suitable telescope is not available, one barrel of an opera glass may be alined with the eye aperture of the range finder and satisfactory results obtained. A prism field glass is not recommended, as the higher magnification and the loss of light by the extra reflections at the prism surfaces make it less desirable for this purpose. If the multiple rows of charts shown in figure 11 are available, the range-finder setting is made on the middle row. If one of the other rows is sharpest on the negative, it indicates that the reading through the range finder has not been accurately made or that the range finder is out of adjustment. The truth of this latter conclusion 
should not be assumed unless the experiment is repeated several times and a consistent failure to focus on the central row is established.

\section{(b) Focusing by Means of Focusing Back}

If the camera has no range finder but is equipped with a focusing back, it is advisable to use it for securing the correct focus. The grain of the ground glass is apt to introduce some uncertainty in deciding upon the best focus. Focusing may be done more precisely if the ground glass is temporarily replaced by a piece of clear glass of the same thickness. Marks should be made near the center of the surface of the glass that corresponds to the ground surface. A wax pencil or a wax crayon, such as comes in children's color sets, is conrenient for this purpose. When looking squarely at the clear glass, the image can be seen only in the center of the field. Focusing must be done with a magnifying lens. The highest power arailable in a simple magnifier is recommended, and focusing is correct when the wax-pencil marks and the image are simultaneously in focus in the field of the magnifying lens.

\section{(c) Focusing by Means of Focusing Scale}

If the camera has no range finder or ground glass but is provided with a focusing scale, it is probable that no indicated value on the scale will correspond exactly to the required distance of $26 f$. In such a case the distance from the chart to the lens may be altered to correspond exactly to the nearest indicated value. If this is done the nominal resolving power read directly from the negative will not be correct, because it will not give the actual number of lines per millimeter. The true resolving power can be found by the following proportion: The actual number of lines per millimeter is to the value read from the chart as the distance from the chart as the distance from the camera to the chart is to 26 focal lengths. When the test is conducted in this manner, results unfavorable to the lens will be obtained if the focusing scale is not accurate, because the lens will have been incorrectly focused for the indicated distance.

Another and perhaps better method of testing a lens on a camera equipped with a focusing scale is arailable. The camera is set up 26 focal lengths from the chart in the usual manner, and the corresponding setting on the focusing scale is estimated from the nearest indicated values. With this setting, if the resulting negative is not satisfactorily sharp, the setting on the scale is left fixed and the distance from the camera to the chart is altered by small steps until an exposure is obtained of satisfactory quality. If the alteration of the distance from 26 focal lengths is not greater than 10 percent, the readings of resolving power will be satisfactorily accurate. If the alteration of the distance has been more than 10 percent, the setting on the focusing scale should be appropriately altered and another series of exposures made, starting again at the distance of $26 f$.

\subsection{Photographic Technique}

The fast or moderately fast film that is commonly used for pictorial photography will resolve from 40 to 50 lines $/ \mathrm{mm}$. A high-grade photographic lens, with a fine-grain high-resolution film, will afford a resolving power much better than this, at least at the center of the field. The resolution that one obtains with a given lensemulsion combination is a function of a large number of parameters, such as resolution of lens, resolution of film, gamma, spectral sensitivity of film, and contrast rendition of filn?. Values of resolving power comparable with those that will be attained in use are obtained by using the films and emulsions that are regularly used. On the other hand, the fine-grain high-resolution film gives results more completely dominated by the lens and therefore is likely to show greater differences between different lenses. Inasmuch as finegrain resolution films and those made for general use differ in other parameters than resolution (spectral sensitivity, contrast rendition, etc.), the correlation of results obtained with fine-grain film and with the more usual low-resolving-power film, although high, is not perfect.

Various methods have been proposed for con!bining resolving power of films and lenses. If, for example, $A$ and $B$ are the resolving powers, respectively, of lens and film, it has been suggested that $C$, the resolving power of the combination, is given by the formula

$$
\frac{1}{C}=\frac{1}{A}+\frac{1}{B}
$$

or

$$
\frac{1}{C^{2}}=\frac{1}{A^{2}}+\frac{1}{B^{2}}
$$

These can, however, be regarded only as approximate formulas to be used for "rule-of-thumb" purposes as the problem is much more complex than is suggested by the formulas.

If one is desirous of choosing a lens-film combination that will give the maximum sharpness, and which, if other things were equal, would give results more characteristic of the lens and less characteristic of the film, then Eastman Panchromatic Micro-file, or Agfa Minipan are suggested. With these films more than 100 lines $/ \mathrm{mm}$ can be clearly resolved if the photographic lens produces an image of the requisite sharpness. For cameras not using motion-picture film, a finegrain film, such as Panatomic $\mathrm{X}$ or Finopan, should be emploved. 'The films giving the highest resolution are of the photomechanical trpe, such as Reprolith or Kodalith.

It is self-evident that there must be no vibration of the camera or charts when the exposures are made. The camera should be on a very rigid tripod or clamped to a table of the proper height, and the charts should be rigidly supported. When there is any doubt about the rigidity of the camera 
support, the following corrective procedure has been found adrantageous. The general illumination is reduced to such an extent that the exposure with the largest diaphram opening is not less than 3 or 4 seconds. When making an exposure the shutter is set at "time," a black card is held immediately in front of the lens but not touching it, and the shutter is opened either by the cable or finger release. After all tremor from opening the shutter has subsided, the card is taken from in front of the lens for the duration of the exposure, then replaced, and the shutter closed. $\mathrm{Br}$ this procedure there is very little likelihood that making the exposure will cause harmful vibrations to the camera.

If one is alreadr familiar with the use of one of the fine-grain developers, it is probably advisable that it should be used, although a fine-grain developer will not increase the resolving power of the emulsion. Most tests of lens resolution at this Bureau have been conducted with buffered $D 76$ [14] and DK20 [15]. The film should be exposed and developed to vield a film of medium density. Exposures should be repeated until a negative, well-focused and of good technical quality, is obtained.

\subsection{Examination of Negative}

On a satisfactory test negative the images should lie on a diagonal of the negative, with the central chart very close to the exact center of the negative. Furthermore, the negative should be of medium density and of first quality, photographically. No attempt should be made to read the ralue of the resolving power until such a negative is obtained. To properly interpret such a negative, it should preferably be examined with a compound microscope magnifying 30 or 40 diameters, although a good magnifying glass, magnifying 10 or 15 diameters, can be used on the coarser patterns. One may also examine the negative indirectly by making a 10 or 15 diameter bromide enlargement from the negative and then using the magnifying glass on the enlargement. When this method is used there is danger that the lens will not be judged fairly, because faults originating in the enlarging may be attributed to the lens under test.

As has been mentioned, the resolving powers for the rertical and horizontal lines are referred to as the tangential and radial resolving powers, respectively. On each chart (of the row in best focus, if multiple rows are used) the finest patterns of vertical and horizontal lines that are resolved are read and counted. A pattern of lines is resolved if the individual lines can be clearly distinguished and if the number of lines is the same as the number of lines in the test chart. This checking of the number of lines is important because diffraction effects sometimes produce a spurious resolution in which the lines are apparently clearly distinguishable on the negative but the total number of lines does not check with the number in the original pattern.
The number of lines per millimeter in each pattern is given in figure 2 and table 3 . Typical results of the tests on lenses of miniature cameras are given in the following section.

\section{Interpretation of Results}

A brief discussion of the resolving-power characteristics as predicted from theoretical considerations [16] is perhaps desirable before proceeding to the problem of interpreting results obtained with the resolution charts. This theory has long been established, and predictions from it will be used in this circular only for the purpose of providing a yardstick against which to compare the performance of lenses. Since the predicted characteristics are for an ideal lens and without limitations imposed by the film, it should not be surprising if experimental results for actual lenses deviate to some extent from those predicted. These deriations result from aberrations inherent in any actual lens. These departures do not however signify that the theory is without value in the prediction of lens performance. In general, the theoretical values are the ultimate that can be expectd under a given set of conditions. Except for very small apertures, observed values are always lower because of the limitation of the film and also because photographic lenses, except when of very narrow field, are not sufficiently well corrected to give the Airy diffraction disk as the image of a point.

\subsection{Maximum Resolving Power of an Ideal Lens}

The smallest separation of two star images theoretically distinguishable on the basis of diffraction of light is, according to the usual criterion,

$$
X=\frac{1.22 F \lambda}{d}
$$

where $X$ is the separation in the image plane, $F$ the focal length of the lens, $d$ the diameter of the lens aperture, and $\lambda$ the wavelength of the incident light. For present purposes, it will be assumed that the same equation is valid when the images are composed of parallel lines instead of points. It is also more convenient to express the maximum resolving power, $N_{m}$ in lines per millimeter. It can be shown that the equation

$$
N_{m}=\frac{1426}{b} \text { lines per millimeter, }
$$

where $b$ is the $f$-number, is equivalent to eq 20 , for $\lambda=575$ millimicrons. This relation is valid for axial imagery. For extra axial points, it is necessary to use the two additional approximate relations, one for maximum resolving power for tangential lines, 


$$
N_{t \beta}=\frac{1426}{b} \cos ^{3} \beta \text { lines per millimeter }
$$

and another for maximum resolving power for radial lines,

$$
N_{r \beta}=\frac{1426}{b} \cos \beta,
$$

where $\beta$ is the angular separation from the axis for the point considered. Table 9 gives the values computed for the resolving power in both orientations at 5-degree intervals from $0^{\circ}$ to $45^{\circ}$ for a series of $f$-numbers, ranging from 4 to 64 , in a form convenient for use. The foregoing discussion and computations are based on the assumption of the object being a great distance from the lens, so that the image plane and focal plane coincide. For finite distances the $f$-number must be multiplied by $(m+1) / m$, where $m$ is the ratio of object distance to image distance. Thus for the value $m=25$, which is suggested for use in testing camera lenses, the values listed in table 9 must be reduced by multiplying by 0.96 . When a lens is used in copying at 1 to $\dot{1}$, the values listed in the table must be halved.

TABLE 9. Maximum attainable resolving power in lines per millimeter for an ideal lens as a function of stop-

\begin{tabular}{|c|c|c|c|c|c|c|c|c|c|c|}
\hline \multirow{2}{*}{$\begin{array}{c}\text { Relative } \\
\text { aperture } \\
(f \text {-number })\end{array}$} & \multicolumn{10}{|c|}{$\begin{array}{c}\text { Resolving power for tangential lines at angular } \\
\text { separation from axis of - }\end{array}$} \\
\hline & $0^{\circ}$ & $5^{\circ}$ & $10^{\circ}$ & $15^{\circ}$ & $20^{\circ}$ & $25^{\circ}$ & $30^{\circ}$ & $35^{\circ}$ & $40^{\circ}$ & $45^{\circ}$ \\
\hline $\begin{array}{l}4 \\
5.6 \\
8 \\
11 \\
16 \\
22 \\
32 \\
45 \\
64\end{array}$ & $\begin{array}{r}356 \\
255 \\
178 \\
130 \\
89 \\
65 \\
45 \\
32 \\
22\end{array}$ & $\begin{array}{r}352 \\
252 \\
176 \\
128 \\
88 \\
64 \\
44 \\
32 \\
22\end{array}$ & $\begin{array}{r}340 \\
244 \\
170 \\
124 \\
85 \\
62 \\
43 \\
31 \\
21\end{array}$ & $\begin{array}{r}321 \\
230 \\
160 \\
117 \\
80 \\
58 \\
40 \\
29 \\
20\end{array}$ & $\begin{array}{r}295 \\
212 \\
148 \\
108 \\
74 \\
54 \\
37 \\
26 \\
18\end{array}$ & $\begin{array}{r}265 \\
190 \\
132 \\
97 \\
66 \\
48 \\
33 \\
24 \\
16\end{array}$ & $\begin{array}{r}231 \\
166 \\
116 \\
84 \\
58 \\
42 \\
29 \\
21 \\
14\end{array}$ & $\begin{array}{r}196 \\
140 \\
98 \\
71 \\
49 \\
36 \\
25 \\
18 \\
12\end{array}$ & $\begin{array}{r}160 \\
115 \\
80 \\
58 \\
40 \\
29 \\
20 \\
14 \\
10\end{array}$ & $\begin{array}{r}126 \\
90 \\
63 \\
46 \\
31 \\
23 \\
16 \\
11 \\
8\end{array}$ \\
\hline & \multicolumn{10}{|c|}{$\begin{array}{l}\text { Resolving power for radial lines and angular separation } \\
\text { from the axis of - }\end{array}$} \\
\hline & $0^{\circ}$ & $5^{\circ}$ & $10^{\circ}$ & $15^{\mathrm{c}}$ & $20^{\circ}$ & $25^{\circ}$ & $30^{\circ}$ & $35^{\circ}$ & $40^{\circ}$ & $45^{\circ}$ \\
\hline \begin{tabular}{l}
\multicolumn{1}{c}{} \\
5.6 \\
8 \\
11 \\
16 \\
22 \\
32 \\
45 \\
64
\end{tabular} & $\begin{array}{r}356 \\
255 \\
178 \\
130 \\
89 \\
65 \\
45 \\
32 \\
22\end{array}$ & $\begin{array}{r}355 \\
254 \\
177 \\
130 \\
89 \\
65 \\
45 \\
32 \\
22\end{array}$ & $\begin{array}{r}351 \\
251 \\
175 \\
128 \\
88 \\
64 \\
44 \\
32 \\
22\end{array}$ & $\begin{array}{r}344 \\
246 \\
172 \\
126 \\
86 \\
63 \\
43 \\
31 \\
21\end{array}$ & $\begin{array}{r}334 \\
240 \\
167 \\
122 \\
84 \\
61 \\
42 \\
30 \\
21\end{array}$ & $\begin{array}{r}323 \\
231 \\
161 \\
118 \\
81 \\
59 \\
41 \\
29 \\
20\end{array}$ & $\begin{array}{r}308 \\
221 \\
154 \\
113 \\
7 \\
56 \\
39 \\
28 \\
19\end{array}$ & $\begin{array}{r}292 \\
209 \\
146 \\
106 \\
73 \\
53 \\
37 \\
26 \\
18\end{array}$ & $\begin{array}{r}273 \\
195 \\
136 \\
100 \\
68 \\
50 \\
34 \\
25 \\
17\end{array}$ & $\begin{array}{r}252 \\
180 \\
126 \\
92 \\
63 \\
46 \\
32 \\
23 \\
16\end{array}$ \\
\hline
\end{tabular}
opening

It must be remembered that these values of resolving power are predicted for the case of an ideal lens. It is unlikely that any actual lens will rield full theoretical resolving power, although values very close to the maximum can be obtained near the center of the field for moderate apertures by using fine-grain slow emulsions, such as Eastman Spectroscopic Plates, $548 \mathrm{GH}$ or $649 \mathrm{GH}$. However, at the large $f$-numbers, it can happen that ordinary emulsions will be able to resolve finer detail than the lens is theoretically capable of resolving. For example, the maximum resolving power of a lens at $f / 32$ is 45 lines $/ \mathrm{mm}$ on the axis, and there are many emulsions in common use that will resolve 60 lines $/ \mathrm{mm}$ or better.

\subsection{Depth of Focus For an Ideal Lens}

When a lens forms an image of an object located at an infinite distance in front of the lens, there exists a small finite range in the image space for which a recognizable image of the object is formed. This range is called "depth of focus" and refers to the distance measured along the axis in the image space that may be traversed without the resolving power, measured in the image plane, falling below an arbitrarily selected value. It is not to be confused with "depth of field", which refers to the range in the object space for which all point objects are imaged with a radius of the circle of confusion remaining less than or equal to some arbitrarily selected value.

It can be shown that the depth of focus, $d_{f}$, in millimeters can be computed from the relation

$$
d_{f}=\frac{4 b}{N}
$$

where $b$ is the $f$-number, and $N$ is the resolving power in lines per millimeter for which the depth of focus is sought eq 24 is based on geometric optics and is restricted to values of $N$ lying between zero and $N_{m}$, where $N_{m}$ is the maximum resolving power computed by eq 21, which is based on physical optics. The value of $d_{f}$ is independent of angular separation from the axis for a given $f$-number, and consequently no additional equations for the off-axis conditions are necessary.

With the aid of eq 24 supplemented by eq 21 , it is possible to compute the probable depth of focus for a given resolving power at a specified $f$-number. The results of such computations are given in table 10 . It may be noted that depth of focus increases with $f$-number for any selected value of the resolving power, and that for a given $f$-number depth of focus increases with decreasing resolving power. It is clear on consideration of

TABLE 10. Maximum depth of focus for an ideal lens as a

\begin{tabular}{|c|c|c|c|c|c|c|}
\hline \multirow{2}{*}{$\begin{array}{l}\text { Rela- } \\
\text { tive } \\
\text { aper- } \\
\text { ture } \\
(f \text {-num- } \\
\text { ber) }\end{array}$} & \multicolumn{6}{|c|}{$\begin{array}{l}\text { Maximum depth of focus for resolving power, in } \\
\text { lines/mm, of - }\end{array}$} \\
\hline & 320 & 160 & 80 & 40 & 20 & 10 \\
\hline $\begin{array}{l}2 \\
2.8 \\
4 \\
5.6 \\
8 \\
11 \\
16 \\
22\end{array}$ & \begin{tabular}{c}
$m m$ \\
0.025 \\
.035 \\
.050 \\
\hdashline \\
\\
\hdashline
\end{tabular} & $\begin{array}{c}m m \\
0.05 \\
.07 \\
.10 \\
.14 \\
.20 \\
\\
\end{array}$ & $\begin{array}{c}m m \\
0.10 \\
.14 \\
.20 \\
.28 \\
.40 \\
.55 \\
.80\end{array}$ & $\begin{array}{r}m m \\
0.20 \\
.28 \\
.40 \\
.56 \\
.80 \\
1.10 \\
1.60 \\
2.20\end{array}$ & $\begin{array}{r}m m \\
0.40 \\
.56 \\
.80 \\
1.12 \\
1.60 \\
2.20 \\
3.20 \\
4.40\end{array}$ & $\begin{array}{l}m m \\
0.80 \\
1.12 \\
1.60 \\
2.24 \\
3.20 \\
4.40 \\
6.40 \\
8.80\end{array}$ \\
\hline
\end{tabular}
function of $f$-number for a series of values of the resolving power in the focal plane 
the values listed in the table that focusing becomes more critical both for smaller $f$-numbers and for finer detail in the image.

It must be mentioned that the values of depth of focus computed from eq 24 for an ideal lens are likely to be larger than the values observed for an actual lens. However, for the actual lens, the depth of focus will usually be at least 62 percent of that computed for the ideal lens, so that the table nonetheless serves as a useful guide. It sometimes happens that a given pattern appears to be resolved over a greater range than that indicated in the table. This is more likely to occur when photographing high-contrast targets. When this does occur, it is frequently a spurious resolution, and consequently some care is required in interpreting the results.

\subsection{Effect of Field Curvature}

It usually happens that a lens does not give uniformly good definition throughout the entire image plane. One may have a condition where the central and edge definition are good but there is an annular zone between the center and edge where the definition is less good. This is usually a consequence of curvature of the image or field curvature. All lenses exhibit this characteristic in varying degree, but when an excessive amount of field curvature is present, it may impair the usefulness of the lens. In order to present a clearer picture of this phenoma, the results of resolving power measurements on a lens are shown in figure 12. Each frame of the figure shows how the resolving power in an image plane of the lens for a target pattern of lines in a given orientation and located at an infinite distance from the lens varies as the image plane moves from a position inside to a position outside best axial focus. For a given frame, the zero of abscissas marks the position of best visual focus on the axis at $f / 5.6$, and positive values indicate positions farther from the lens. The region of useful imagery for tangential, $T$, and radial, $R$, lines are shown for the aperture ratios, $f / 5.6$ and $f / 11$ for each 5-degree interval of angular separation from the axis.
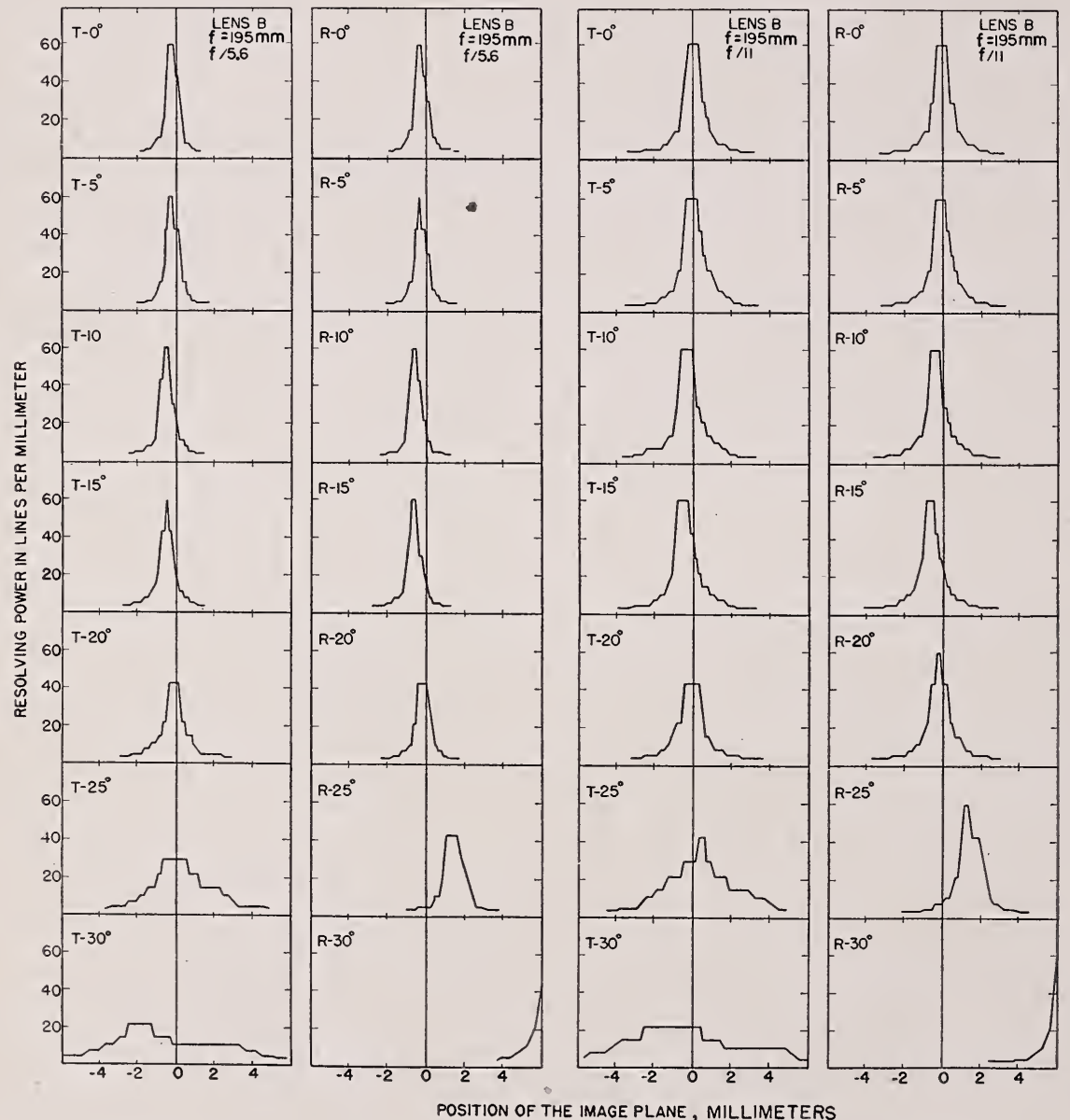

FIGURE 12. Resolving power versus position of the image plane for an actual lens at apertures $\mathrm{f} / 5.6$ and $\mathrm{f} / 11$.

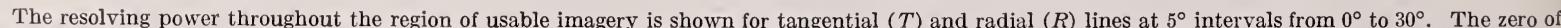

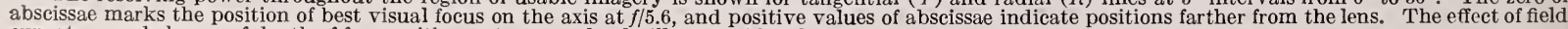
curvature and change of depth of focus with aperture are clearly illustrated by these curves. 
Examination of these curves shows that the resolving power in the image plane rises to a maximum and falls in rery similar fashion for both tangential and radial line patterns as the image plane moves through the image forming region throughout the entire angular field of the lens. If one considers a single vertical array of curves, for example, those marked $T-0^{\circ}$ to $T-30^{\circ}$, inclusive, it is evident that the maxima of these curves do not all occupy the same position with respect to the zero of abscissa, which marks the position of the plane of best visual focus on the axis. This results from the fact that the surface of best focus for a lens is not a true plane but is instead a curred surface. This phenomenon is referred to as field curvature. In addition, there is a difference between the surfaces of optimum definition for tangential lines (i. e., lines drawn tangent to circles with a point on the optical axis as center) and radial lines (i. e., lines parallel to radii drawn from a point on the optical axis). Curves drawn showing the position of these maxima are called curres of primary (for tangential lines) and secondary (for radial lines) curvature. Such curves are illustrated in figure 13.

It may also be noted that the tangential and radial maxima of resolving power do not alwars occur at the same position. This is particularly noticeable in figure 12 for $T-25^{\circ}$ and $R-25^{\circ}$, where the separation along the axis amounts to approximately $2 \mathrm{~mm}$. Consequently, when the tangential lines are clearly resolved by this lens, the radial are poorly resolved. This effect is called astigmatism, and the measured difference between the two maxima is called the astigmatic difference.

It is clear from the above considerations that optimum imagery throughout the image plane is seldom possible for any actual lens at its maximum stop opening. Fortunately, however, most users do not have occasion to strain the capabilities of their equipment, since the resolving powers of emulsion in common usage are considerably below that of the lens. Because of this, it is usually possible to select a compromise focus where a small reduction in resolution on the axis is accepted in order to obtain tolerable resolution throughout the extra-axial regions. This is the idea underlying the concept of the image plane of best a verage definition as opposed to the image plane of best axial focus.

The effect of curvature of field is masked in a rery large degree when the lens is stopped down. This effect is clearly shown in figure 12 when the curves of resolving power rersus position of the image plane for relative aperture $f / 5.6$ are compared with those for relative aperture $f / 11$. The increase in depth of focus with increasing $f$-number, as predicted in eq 24, is clearly shown in these illustrations. Because of the increased depth of focus with decreased stop opening, a general improvement in definition throughout the image plane is frequently encountered when the imagery obtained with a lens set at a small stop opening is compared with that obtained with the same lens set at a larger stop opening. this behavior seems to be at rarian

which predicts that the resolving

given part of the image plane is a maximum at

largest stop opening. Howerer, the imag.

ture usually precludes the positioning of plane so that all resolving porer maxima for all angular separations from the axis are present therein. On the contrary, any given image plane can contain only a few of the maxima, and the small depth of focus existing at the larger stop openings for maximum resolving power at various angular separations from the axis further serves to limit the number of maxima obtainable in the image plane.

When an image plane has been selected which contains sereral resolving power maxima and is held fixed while the stop opening is reduced, it is clear that the depth of focus increases for all maxima. Consequently, there is greater likelihood of the given image plane including more maxima than it did at the full stop opening, and, as a result, the definition considered throughout the entire image plane will show improvement. In fact, some improvement is likely, even if more maxima are not included because the increased

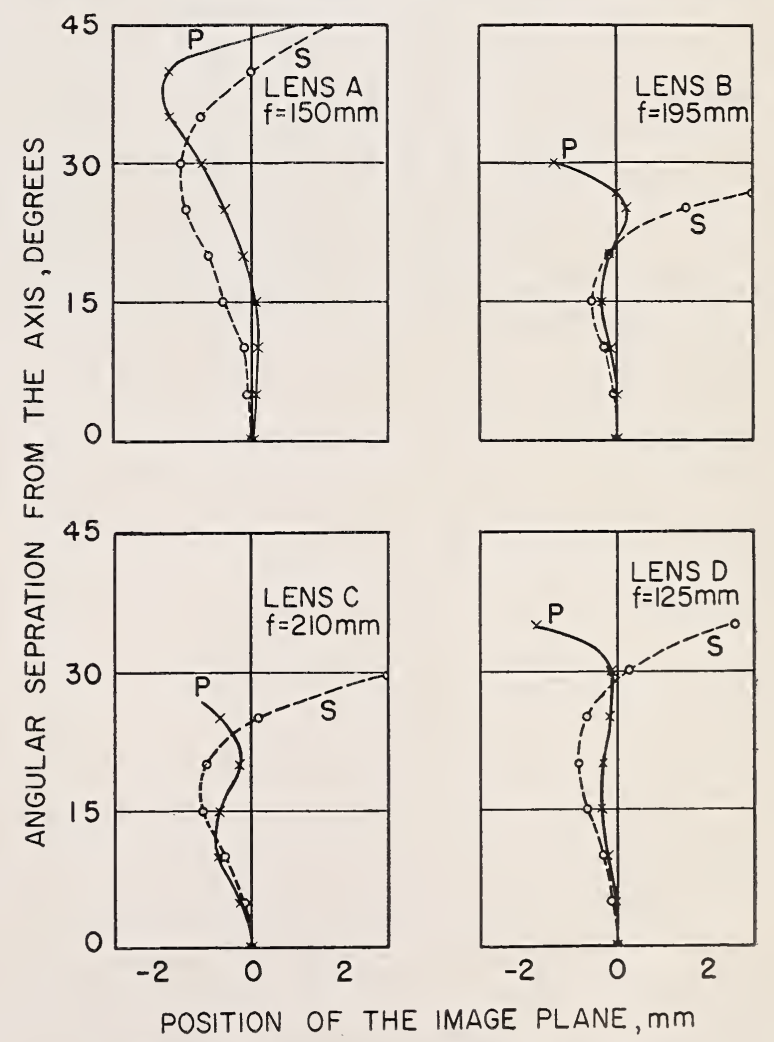

Figure 13. Field curvature for four types of lens.

Curve $P$ shows the primary curvature and is the locus of the positions of maximum resolving power for tangential lines at the indicated angular separations from the axis. Curve $S$ shows the secondary curvature and is the focus of radial lines at focus of the positions of maximum radial resolving power for radial lines at the indicated angular separations from the axis. The zero abscissae marks
the position of best axial focus and positive ralues of abscissae indicate posithe position of best axial focul
tions farther from the axis. 
depth of focus for any selected value of the resolving power makes it probable that some regions will be benefited br an increase in resolving power, even if additional maxima are not reached. This type of improvement of definition does not continue indefinitely with diminishing stop opening. Ultimately the limitations set by diffraction theory become significantly effective, and the maximum resolving power of the lens falls below the resolving power of the emulsion, and the overall definition then begins to worsen with diminishing stop opening.

\subsection{Experimental Results of Actual Lenses}

The primary purpose of this Circular is the description of these test charts and the methods of use. However, it may be of interest to list some results obtained in using these charts for the testing of a representative group of lenses. The results of tests will be discussed under the categories (a) experimental results with the highcontrast chart and (b) comparative results on axis for high- and low-contrast chart. The greater emphasis will be placed on the high-contrast targets, as this type of chart has been widely used for a long period of time. It is probable that the low-contrast chart will be used more extensively if the results of current research indicate that lens ratings obtained therewith prove as useful as those obtained with the high-contrast chart.

\section{(a) Experimental Results with High-Contrast Chart}

The resolving powers of five lenses of the type used on small hand-held cameras were determined, using the procedures described in section 8 . In addition, the resolution of a pinhole camera was determined. The values of the resolving power of these lenses for several apertures are listed in table 11. The lenses were chosen at random, and the values listed should not be generalized as characteristic of any particular make or type of lens. The lenses tested include both foreign and domestic products.

Eastman Panchromatic Microfile film was used in making the test negatives for lenses $A$ and $B$. Eastman Spectroscopic plate, trpe V-B was used for lens $C$. Eastman Plus-X film was used for lenses $D$ and $E$. Eastman Panchromatic plate was used for the pinhole camera $F$. The negatives for $A, B, D$, and $E$, from which some of the measurements were made, have been enlarged and are reproduced in figure 14 . It is unlikely that any of the finer patterns will be resolved in the reproduction, as they were in the original negatives. However, an examination of the coarser patterns will show differences in the quality of definition and some of the effects of astigmatism at the larger angles.

In table 11, it is clear that the values of resolution for axial imagery are usually higher than for other portions of the field. This is to be expected
TABLE 11. Resolving power at various apertures of several. lines of the type used on small hand-held cameras

\begin{tabular}{|c|c|c|c|c|c|c|c|c|c|c|c|c|}
\hline \multirow{3}{*}{ Lens } & \multirow{3}{*}{$\begin{array}{l}\text { Equir- } \\
\text { alent } \\
\text { focal } \\
\text { length }\end{array}$} & \multirow{3}{*}{$\begin{array}{c}\text { Rela- } \\
\text { tive } \\
\text { aper- } \\
\text { ture } \\
\text { (f-num- } \\
\text { ber })\end{array}$} & \multicolumn{10}{|c|}{$\begin{array}{l}\text { Resolving power in lines per millimeter } \\
\text { (angular separation from axis) }\end{array}$} \\
\hline & & & \multicolumn{5}{|c|}{ Tangential } & \multicolumn{5}{|c|}{ Radial } \\
\hline & & & $0^{\circ}$ & $5^{\circ}$ & $10^{\circ}$ & $15^{\circ}$ & $20^{\circ}$ & $0^{\circ}$ & $5^{\circ}$ & $10^{\circ}$ & $15^{\circ}$ & $20^{\circ}$ \\
\hline A. & $m m$ & $\mid \begin{array}{l}2 \\
2.8 \\
4 \\
5.6 \\
8 \\
11 \\
16 \\
22\end{array}$ & $\begin{array}{l}68 \\
68 \\
80 \\
80 \\
80 \\
80 \\
56 \\
56\end{array}$ & $\begin{array}{l}56 \\
68 \\
68 \\
80 \\
68 \\
80 \\
56 \\
56\end{array}$ & $\begin{array}{l}56 \\
68 \\
56 \\
68 \\
68 \\
80 \\
56 \\
48\end{array}$ & $\begin{array}{l}48 \\
68 \\
56 \\
68 \\
68 \\
80 \\
56 \\
48\end{array}$ & $\begin{array}{l}28 \\
56 \\
56 \\
80 \\
68 \\
68 \\
48 \\
48\end{array}$ & $\begin{array}{l}68 \\
68 \\
80 \\
80 \\
80 \\
80 \\
56 \\
56\end{array}$ & $\begin{array}{l}56 \\
68 \\
68 \\
80 \\
68 \\
80 \\
56 \\
56\end{array}$ & $\begin{array}{l}56 \\
68 \\
68 \\
80 \\
68 \\
80 \\
48 \\
48\end{array}$ & $\begin{array}{l}48 \\
68 \\
68 \\
80 \\
68 \\
80 \\
48 \\
48\end{array}$ & $\begin{array}{l}40 \\
56 \\
68 \\
80 \\
56 \\
80 \\
48 \\
40\end{array}$ \\
\hline B & 50 & $\begin{array}{c}4.5 \\
5.6 \\
8 \\
11 \\
16\end{array}$ & $\begin{array}{l}56 \\
56 \\
56 \\
56 \\
56\end{array}$ & $\begin{array}{l}34 \\
28 \\
28 \\
34 \\
56\end{array}$ & $\begin{array}{l}20 \\
17 \\
24 \\
34 \\
56\end{array}$ & $\begin{array}{l}14 \\
20 \\
34 \\
34 \\
48\end{array}$ & $\begin{array}{l}24 \\
34 \\
48 \\
56 \\
48\end{array}$ & $\begin{array}{l}56 \\
56 \\
56 \\
56 \\
56\end{array}$ & $\begin{array}{l}40 \\
40 \\
56 \\
56 \\
56\end{array}$ & $\begin{array}{l}40 \\
40 \\
48 \\
56 \\
56\end{array}$ & $\begin{array}{l}48 \\
56 \\
80 \\
80 \\
68\end{array}$ & $\begin{array}{l}48 \\
56 \\
80 \\
80 \\
68\end{array}$ \\
\hline $\mathrm{C}_{-}$ & 85 & $\left\{\begin{array}{c}2 \\
5.6 \\
11\end{array}\right.$ & $\begin{array}{l}68 \\
68 \\
68\end{array}$ & $\begin{array}{l}68 \\
68 \\
68\end{array}$ & $\begin{array}{l}34 \\
48 \\
48\end{array}$ & $\begin{array}{l}17 \\
20 \\
24\end{array}$ & & $\begin{array}{l}68 \\
68 \\
68\end{array}$ & $\begin{array}{l}68 \\
68 \\
68\end{array}$ & $\begin{array}{l}48 \\
68 \\
68\end{array}$ & $\begin{array}{l}34 \\
56 \\
80\end{array}$ & $\ldots$ \\
\hline D & 101 & $\begin{array}{c}4.5 \\
5.6 \\
8 \\
11 \\
16\end{array}$ & $\begin{array}{l}34 \\
40 \\
40 \\
40 \\
34\end{array}$ & $\begin{array}{l}34 \\
34 \\
40 \\
48 \\
48\end{array}$ & $\begin{array}{l}28 \\
28 \\
40 \\
48 \\
48\end{array}$ & $\begin{array}{l}28 \\
28 \\
34 \\
40 \\
40\end{array}$ & $\begin{array}{l}28 \\
28 \\
34 \\
40 \\
40\end{array}$ & $\begin{array}{l}34 \\
40 \\
40 \\
40 \\
34\end{array}$ & $\begin{array}{l}34 \\
40 \\
48 \\
48 \\
48\end{array}$ & $\begin{array}{l}28 \\
28 \\
48 \\
48 \\
48\end{array}$ & $\begin{array}{l}20 \\
14 \\
24 \\
34 \\
40\end{array}$ & $\begin{array}{l}28 \\
28 \\
28 \\
34 \\
40\end{array}$ \\
\hline $\mathrm{E}_{-}$ & 101 & $\begin{array}{l}4.5 \\
5.6 \\
8 \\
11 \\
16 \\
22 \\
32\end{array}$ & $\begin{array}{l}28 \\
28 \\
34 \\
28 \\
34 \\
34 \\
34\end{array}$ & $\begin{array}{l}28 \\
28 \\
28 \\
28 \\
34 \\
28 \\
28\end{array}$ & $\begin{array}{l}24 \\
20 \\
24 \\
28 \\
28 \\
28 \\
24\end{array}$ & $\begin{array}{l}12 \\
12 \\
17 \\
20 \\
17 \\
17 \\
17\end{array}$ & $\begin{array}{r}7 \\
7 \\
14 \\
12 \\
12 \\
5 \\
12\end{array}$ & $\begin{array}{l}28 \\
28 \\
34 \\
28 \\
34 \\
34 \\
34\end{array}$ & $\begin{array}{l}34 \\
28 \\
34 \\
40 \\
40 \\
40 \\
34\end{array}$ & $\begin{array}{l}34 \\
34 \\
34 \\
40 \\
40 \\
40 \\
34\end{array}$ & $\begin{array}{l}28 \\
28 \\
28 \\
28 \\
28 \\
34 \\
34\end{array}$ & $\begin{array}{l}20 \\
20 \\
28 \\
28 \\
20 \\
24 \\
28\end{array}$ \\
\hline & & & 5.6 & 5.6 & 5.6 & 5.6 & 4.8 & 5.6 & 5.6 & 5.6 & 4.8 & 4.8 \\
\hline
\end{tabular}

in consequence of field curvature. Astigmatic differences are also noticeable. Lens $A$ demonstrates the improvement in over-all definition that results when the lens is stopped down; at $f / 11$, this lens is resolving 80 lines $/ \mathrm{mm}$ for all regions except at $20^{\circ}$, where the resolution for tangential lines falls to 68 lines $/ \mathrm{mm}$.

The emulsions of both Microfile film and Spectroscopic plates have resolution in excess of 100 lines $/ \mathrm{mm}$. Consequently, the limit of resolution is chiefly determined by the lens or chart and not the emulsion. Lens $B$ has the same focal length as $A$ but yields 56 lines $/ \mathrm{mm}$ on the axis. Consequently, it cannot be used to resolve as fine detail as $A$. Lens $C$ resolves 68 lines $/ \mathrm{mm}$ on the axis, but it has a greater focal length than $A$. Therefore, to compare results of $A$ and $C$ for resolution of object detail, the values obtained for $C$ should be multiplied by the ratio of focal lengths, which is in this case 1.7. The product of 68 and 1.7 is 115 , hence $C$ will show finer object detail than $A$ on the axis, but is lower in performance in the extra-axial region at 15 degrees.

While the resolution of Plus-X emulsion is not as high as Microfile, nonetheless, it is sufficiently high that it can be used satisfactorily, particularly for the longer focal length lenses, such as $D$ and $E$. The performance of lenses $D$ and $E$ cannot fairly be compared with lenses $A$ and $B$ because of the difference in emulsion used. 


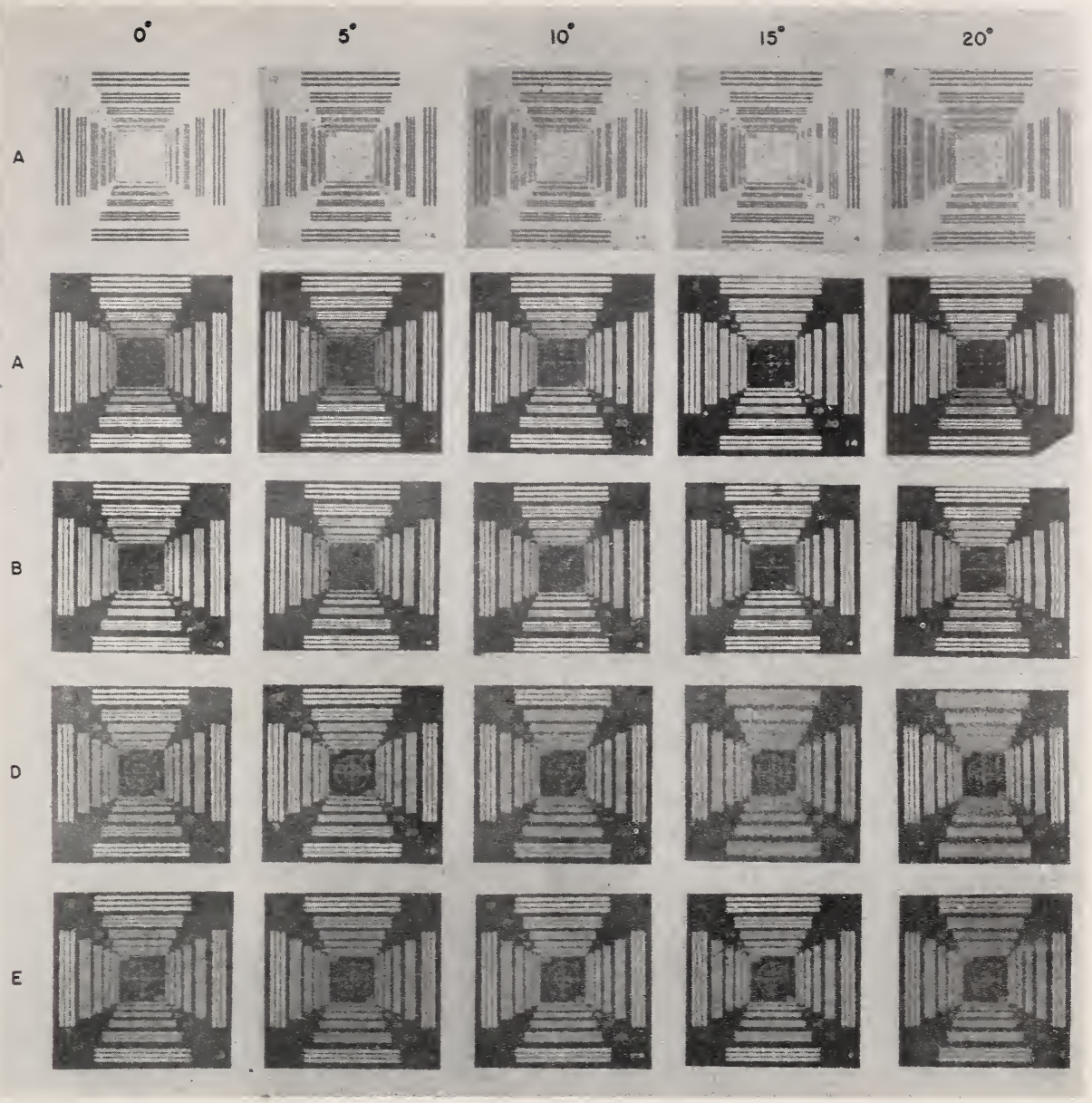

FIGURE 14. Results of tests of resolving power.

Halftone reproductions of enlargements made from negatives for four of the lenses whose test results are listed in table 11. The upper row is a black and white reproduction of a Kodachrome negatice made with lens . 1 . Nicrofile film was used in obtaining the negatices for the second and third rows for lenses $A$ and $B$. Plus- $X$ film was used for lenses $D$ and $E$.

It is interesting to note, however, that when the values of resolving power obtained for lenses $D$ and $E$ are multiplied br 2 (i. e., ratio of the focal lengths) the adjusted values compare favorably with those obtained for lenses $A$ and $B$.

The subject of rating lenses is a somewhat controversial one because of the natural tendency of each worker in the field to develop a method that is sufficient for his own particular purpose. Such rating methods are quite satisfactory so long as one remembers that each method has its limitations and ought not to be considered as applicable to all types of lenses. For example, a rating method for copving cameras where high speed is not required cannot be applied to airplanecamera lenses, where high speed is important. The requirements for a lens whose negatives are always contact printed should be different from those for lenses whose negatives are to be enlarged. For the use of small hand-held cameras, perhaps the simplest method of rating lenses is to compute the degree of enlargement possible before it becomes evident that further enlargement does not add to the detail otservable to the eve at normal viewing distance. Tiewing distance varies for different people but usually lies within the range from 10 to 14 inches. 'The average eye cannot distinguish detail finer than 7 lines $/ \mathrm{mm}$ at 10 inches or 5 lines $/ \mathrm{mm}$ at 14 inches. 'Taking the 14-inch distance as the more usual, then a negative mar be enlarged until the coarsest detail is 5 lines $/ \mathrm{mm}$. For most pictorial subjects, even greater coarseness of detail will be satisfactory, particularly at the corners or edge of the field. On the basis of a 14 -inch viewing distance and a 5 lines $/ \mathrm{mm}$ minimum in the enlargement, it is evident that so far as axial imagery is concerned. all 5 lenses, $A$ through $E$, are satisfactory for all indicated apertures. At aperture $f / 5.6$, considering imager y throughout the field, lenses $A$ and $C$ will rield satisfactory enlargements. At aperture $f / 11$, lenses $A, B, C$, and $D$ will rield satisfactorr enlargements.

The resolution of the pinhole camera, listed as lens $F$ in table 11 , is of course very low because of the very small relative aperture. Howerer, 
it is interesting to note that this low resolution is of the same order of magnitude as the resolving power of the eye at a viewing distance of 14 inches. Consequently, contact prints of the negative made with this camera will contain all the detail that can be readily seen with the unaided eye.

It is probable that a lens that yields high values of the resolving power with a fine-grain panchromatic film when tested with the aid of the highcontrast charts will have a high degree of color correction. Some support for this belief was obtained by photographing the high-contrast charts with Kodachrome film with lens $A$. The values of the resolving power observed on the color negative were essentially the same as those shown in table 11 for lens $A$. A reproduction of this negative is shown in figure 14 . The fact that values of 80 lines $/ \mathrm{mm}$ were obtained throughout most of the image field suggests that this type of film might well be used in testing cameras for which other types of fine-grain film may not be readily obtainable.

The black and white lines of the image on the color film for lens $A$, as viewed through a microscope, were reproduced accurately, with no trace of color at the edges of the tangential lines. If appreciable amounts of chromatic aberration were present in the lens, the patterns for the different colors would not be exactly the same size, color fringes would appear, and the white spaces sepa-

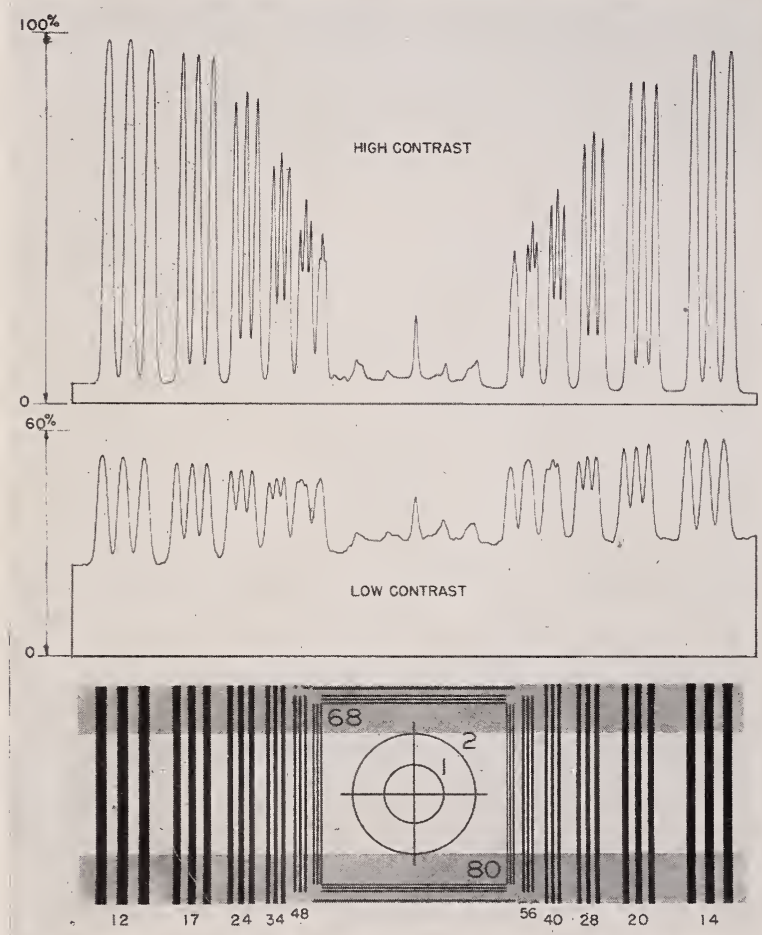

FIgURE 15. Comparative results on axis for a lens tested with high-and low-contrast charts.

These curves are microdensitometer traces made by scanning the negative images of the high-and low-contrast charts. The light area of the reproduction of the chart at the bottom of the figure shows the portion of the image actually scanned. rating the black lines would have colored edges. This effect would be most pronounced for the tangential lines near the edge of the image area. Although the number of tests made with the color film were few in number, the results indicate that the charts may be used to determine the suitability of a lens for use in taking photographs in color.

\section{(b) Comparative Results on Axis for High- and Low- Contrast Charts}

The same arrangement of charts and positioning of the camera, described in section 8.1 for testing with the high-contrast chart can be used with the low-contrast chart. In some cases, it may be desirable to use both simultaneously. In this event, the two types of chart can be placed side by side or above one another, as preferred. The values of the resolving power determined for the low-contrast chart will usually be lower than those obtained with the high-contrast chart. The interpretation can be done visually in a satisfactory manner. However, if one has access to a recording microdensitometer, the interpretation can be done with its aid. The difference in performance of a lens for the 2 types of chart, as determined with the aid of a recording microdensitometer, is shown in figure 15 .

In making this test, the 2 charts were placed side by side and photographed at the standard distance of $26 f$. The charts were located at approximately $2.5^{\circ}$ from the axis and on opposite sides thereof. Consequently, the imagery for both can be regarded as near axial. In addition, the symmetrical location of the charts insures that the imagery is being compared under the same experimental conditions. The images were registered on Eastman V-G emulsion. The exposed plate was processed in Eastman D-19 developer at $68^{\circ} \mathrm{F}$ for 3 minutes. The microdensitometer traces of the two images were made with the in-

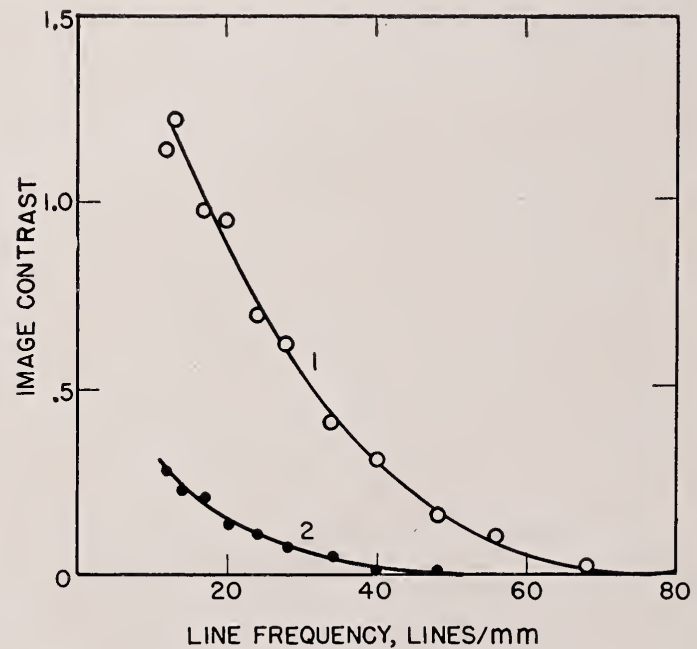

FIGURE 16. Tariation of contrast in the image as a function of line frequency

These curves show the measured values of image contrast taken from the traces shown in figure 14 . Curve 1 shows the results for the high-contrast target and curve 2 shows the results for the low-contrast target. 
strument operating at the same sensitivity. The area of each negative actually scanned is indicated $\mathrm{br}$ the light area of the reproduction of the chart shown at the bottom of figure 15 . The transrerse scale of the reproduction of the chart and the microdensitometer traces are the same in the figure. The microdensitometer traces and the reproduction of the chart are so placed in the figure that ready comparison of the performance of the lens for any pattern of both high- and low-contrast chart is facilitated. For either trace, the distance between the peaks and the ralleys is a measure of the contrast in the image. On the original traces, it is clearly evident that the 68 -line pattern is resolved for the high-contrast chart, whereas the 48 -line pattern is the finest one definitely resolved for the low-contrast chart.

The curves in figure 16 show the manner in which contrast in the image decreases, as the indicated resolving power or line frequency in lines per millimeter increases [12]. Curve 1 shows the results for the high-contrast target (target contrast approximately 1.4), and curve 2 shows the results for a low-contrast target (target contrast approximately 0.17 , which is somewhat lower than that of the low-contrast charts provided with this Circular). The emulsion used in this test has a fairly high contrast. When similar tests are performed with low-contrast emulsions, the image contrasts obtained will be lower, and the observable resolving power will be lower than those shown for the $V-G$ emulsion.

\section{Additional Uses of Test Chart}

Because the test chart in NBS Circular 428 was found useful for so many optical tests performed in the testing of goggles, sunglasses, and telescopes, it was thought advisable to include a discussion of such uses. It has been used mainly in connection with definition tests and for this purpose the chart is specified for use in testing for compliance with the following specifications.

\begin{tabular}{|c|c|}
\hline $\begin{array}{l}\text { Federal Specifica- } \\
\text { tion: } \\
\text { GGG-G-501b_-- }\end{array}$ & $\begin{array}{l}\text { Goggles, eyecup, protective, im- } \\
\text { pact-r esisting (chippers', } \\
\text { grinders', etc.). } \\
\text { Goggles, eyecup, protective } \\
\text { (welders). } \\
\text { Transits, 1-minute; and transit } \\
\text { tripods. }\end{array}$ \\
\hline $\begin{array}{l}\text { U. S. Army Speci- } \\
\text { fication: } \\
51-70-2 \mathrm{C}\end{array}$ & $\begin{array}{l}\text { Optical components for fire } \\
\text { control instruments; general } \\
\text { specification governing the } \\
\text { manufacture, assembly, and } \\
\text { inspection of. }\end{array}$ \\
\hline CS159-49_.... & $\begin{array}{l}\text { Sun glass lenses made of ground } \\
\text { and polished plate glass there- } \\
\text { after thermally curved. }\end{array}$ \\
\hline
\end{tabular}

\subsection{Test for Goggles and Sunglasses}

(a) Prismatic Power

Federal specifications usually require that goggle lenses should, among other requirements, be free from prism effect caused by nonparallelism of the lens surfaces, be free from refractive power, and not lower the visual acuity of the user. Because it is impracticable to eliminate these defects in their entiretr, tolerances for each have been established. In the case of nonparallelism of surfaces, the prism effect must not exceed 1/16 prism diopter (4 minutes angle between surfaces). Lenses shall not be negative in refractive power in any meridian and shall not have in any meridian a positive refractive power exceeding $+1 / 16$ diopter. A line pattern with lines separated not more than 24 seconds should be clearly distinguishable when riewed through the lens placed in front of an 8-power telescope.

In order that the charts, accompanying this Circular, will enable the user to test for prismatic power of goggle lenses, a prism target has been included to permit the detection of prism effect in excess of $1 / 16$ diopter. The 2 concentric circles in the center of the chart are of such size that their radii subtend angles of 1 and 2 minutes when riewed at a distance of 35 feet. A simple $1 / 16$ diopter prism having a refractive index of 1.5 will deviate a beam of light by 2 minutes of arc. Consequently, when properly used, this chart can be used as a go-not-go test for prismatic effect on goggle lenses. The arrangement for testing a goggle lens is shown in figure 17 .

The exact statement of the test from Federal Specification GGG-G-501b is as follows: "Prismatic power.-The lenses are to be tested for prismatic power with an 8-power telescope which has an effective aperture of 0.75 inch and is equipped with cross hairs in the focal plane of the ocular. The telescope is to be focused on an illuminated target, placed at a distance of 35 feet from the telescope objective, comprising a central dot and a concentric circle 0.5 inch in diameter. The telescope is to be so alined that the image of the central dot falls on the intersection of the cross hairs in the focal plane of the ocular. The lens is to be held in front of the objective lens of the telescope and if the intersection point of the cross hairs falls without the image of the circle, the prismatic power of the goggle lens exceeds $1 / 16$ prism diopter.'

It is worthy of mention that the use of telescopes having more than 8-power or with an effective aperture other than 0.75 inch will not necessarily lead to erroneous values. The advantage of the low power is that the imagery is less likely to be blurred if appreciable refractive power is also present in the lens under test. Use of telescopes having less than 8-power leads to considerable uncertainty in the determination because the limit of resolution of the eye is usually not less than 1 minute. Use of telescopes having 

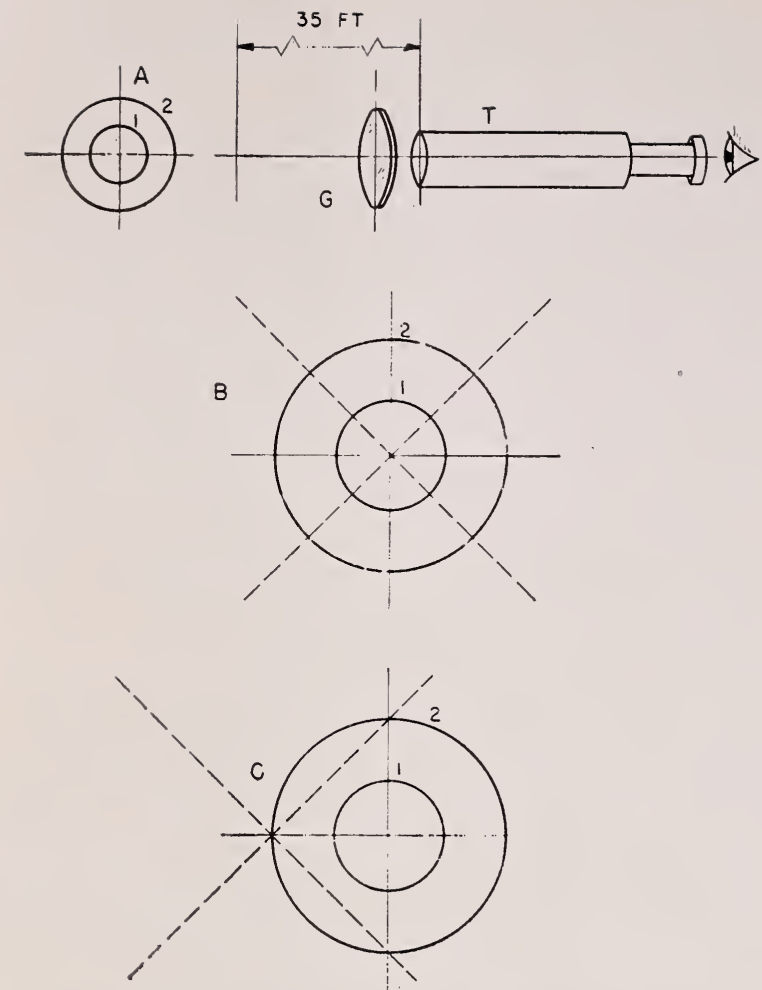

FIGURE 17. Arrangement of chart and telescope for testing goggle lenses.

The upper portion of the figure shows the relative positions of chart $A$, telescope $T$, and goggle lens $G$. When no goggle is in front of telescope $T$, the cross-hairs in the occular of the telescope are superimposed upon the image of cross-hairs in the occular of the telescope are superimposed upon the image of 4 minutes of arc, is placed in front of $T$, the cross-hairs are displaced as shown
the chart as shollel by in $\mathrm{C}$.

as much as 20-power or higher is satisfactory, but in such cases it may be necessary to reduce the effective aperture of the telescope to achieve sufficient depth of focus to minimize the blurring that may arise from refractive power in the goggle lens. Caution should be exercised in the reduction of effective aperture that it not fall below the pupil diameter of the average eye.

\section{(b) Refractive Power of Goggles}

The same arrangement shown in figure 17 can also be used to measure refractive power, provided the focusing movement of the telescope is suitably calibrated. It is usually convenient to use an externally focusing telescope with a rack and pinion movement. The instrument is calibrated for zero power by focusing on the test chart and then scratching a suitable index line on the draw tube to show the position of zero power. A standard lens of $+1 / 16$ diopter power is then placed in front of the objective and the position of best focus found. This position is also marked. Thereafter when testing goggle lenses, if the position of best focus falls within the range between these two marks, the lens satisfies the refractive power tolerance ranging from 0 to $+1 / 16$ diopter. If a standard $+1 / 16$ diopter lens is not readily available, a standard $+1 / 8$ diopter lens may be used. In this case, it is necessary to accurately halve the distance between the zero and $1 / 8$ marks and mark this halfway point as $+1 / 16$ diopter.

\section{(c) Definition Test}

The same arrangement shown in figure 17 can also be used in conducting a definition test. In Federal Specification GGG-G-501b, the definition requirement is that pattern No. 20 shall be clearly resolved at a target distance of 35 feet. The line spacing for pattern No. 20 in the present chart is the same as that for pattern No. 20 in NBS Circular 428. Consequently, the new chart can be satisfactorily used to test the definition requirements.

\subsection{Resolution Test for Telescopes and Binoculars}

It is frequently desirable to determine the limit of resolution for telescopes and binoculars. The limit of resolution is defined as the smallest angle separating 2 points for which the 2 points are still distinguishable as separate points. The theoretical limit of resolution for a telescope can be approximately determined from the formula

Limit of resolution in seconds $=$

$$
\text { diameter of objective in inches }
$$

However, it sometimes happens that a telescope is diaphragmed in a manner not clearly noticeable, so that the effective aperture is reduced. The above relation is then no longer true. In addition, various lens aberrations tend to increase the limit of resolution, so that the only satisfactory way to determine the limit of resolution is by measurement. It has been shown at various times that the limiting angle of resolution for lines is substantially the same as that for points. Consequently, the line patterns in the new chart can be readily used to determine limit of resolution. To do this, it is only necessary to view the chart through the telescope under test, with the chart placed at some convenient distance in front of the objective.

For the convenience of the user, the angular separations of the line elements of the various patterns have been computed for a series of distances and are listed in table 12. Similarly, table 13 gives the angles subtended by the circle targets. To make a determination of the limit of resolution, it is only necessary to view the target through the telescope at a given distance and note the last pattern that is distinctly resolved. The limit of resolution can 
then be found in table 12 . It must be remembered that the magnification used must be high enough to make the readings significant. If the limit of resolution of the eye is assumed to be 1 minute, then the product of the limit of resolution and magnification of the telescope must exceed 60 seconds before one can assume that the eye is not the limiting factor in the determination. It is frequently desirable to place an auxiliary telescope behind the telescope being tested in order to make certain that the overall magnification is sufficiently great.

TABLE 12. Angular separation of lines in the various patterns at different viewing distances

\begin{tabular}{|c|c|c|c|c|c|}
\hline \multirow{2}{*}{$\begin{array}{l}\text { Pattern } \\
\text { number }\end{array}$} & \multirow{2}{*}{$\begin{array}{l}\text { Line } \\
\text { width }\end{array}$} & \multicolumn{4}{|c|}{ Angular separation for a target distance of- } \\
\hline & & $25 \mathrm{ft}$ & $35 \mathrm{ft}$ & $50 \mathrm{ft}$ & $100 \mathrm{ft}$ \\
\hline $\begin{array}{l}80 \\
56 \\
40 \\
28 \\
20 \\
14\end{array}$ & $\begin{array}{r}m m \\
0.31 \\
.45 \\
.62 \\
.89 \\
1.25 \\
1.79\end{array}$ & $\begin{array}{c}\text { Seconds } \\
8.5 \\
12.1 \\
16.9 \\
24.2 \\
33.8 \\
48.3\end{array}$ & $\begin{array}{c}\text { Seconds } \\
6.0 \\
8.6 \\
12.1 \\
17.3 \\
24.2 \\
34.5\end{array}$ & $\begin{array}{c}\text { Seconds } \\
4.2 \\
6.0 \\
8.5 \\
12.1 \\
16.9 \\
24.2\end{array}$ & $\begin{array}{c}\text { Seconds } \\
2.1 \\
3.0 \\
4.2 \\
6.0 \\
8.5 \\
12.1\end{array}$ \\
\hline $\begin{array}{l}68 \\
48 \\
34 \\
24 \\
17 \\
12\end{array}$ & $\begin{array}{r}0.37 \\
.52 \\
.74 \\
1.04 \\
1.47 \\
2.08\end{array}$ & $\begin{array}{l}10.0 \\
14.1 \\
19.9 \\
28.2 \\
39.8 \\
56.4\end{array}$ & $\begin{array}{r}7.1 \\
10.1 \\
14.2 \\
20.1 \\
28.4 \\
40.3\end{array}$ & $\begin{array}{r}5.0 \\
7.0 \\
10.0 \\
14.1 \\
19.9 \\
28.2\end{array}$ & $\begin{array}{r}2.5 \\
3.5 \\
5.0 \\
7.1 \\
10.0 \\
14.1\end{array}$ \\
\hline
\end{tabular}

TABLE 13. Dimensions of circle targets and angular subtenses at a series of viewing distances

\begin{tabular}{|c|c|c|c|c|c|}
\hline \multirow{2}{*}{$\begin{array}{l}\text { Circle } \\
\text { number }\end{array}$} & \multirow{2}{*}{ Radius } & \multicolumn{4}{|c|}{$\begin{array}{l}\text { Angle separating center and periphery for } \\
\text { target distance of }-\end{array}$} \\
\hline & & $25 \mathrm{ft}$ & $35 \mathrm{ft}$ & $50 \mathrm{ft}$ & $100 \mathrm{ft}$ \\
\hline $\begin{array}{l}1 .- \\
12 .-\end{array}$ & $\begin{array}{l}m m \\
3.09 \\
6.19\end{array}$ & $\begin{array}{l}\min \\
1.4 \\
2.8\end{array}$ & $\begin{array}{l}\min \\
1.0 \\
2.0\end{array}$ & $\begin{array}{l}\min \\
0.70 \\
1.4\end{array}$ & $\begin{array}{r}\min \\
0.35 \\
.70\end{array}$ \\
\hline
\end{tabular}

\begin{tabular}{|c|c|c|c|c|}
\hline \multirow{2}{*}{$\begin{array}{l}\text { Width of lines } \\
\text { forming circles } \\
\text { and cross }\end{array}$} & \multicolumn{4}{|c|}{$\begin{array}{l}\text { Angle subtended by width of line for target } \\
\text { distance of - }\end{array}$} \\
\hline & $25 \mathrm{ft}$ & $35 \mathrm{ft}$ & $50 \mathrm{ft}$ & $100 \mathrm{ft}$ \\
\hline 0.155 & $\begin{array}{l}\text { Seconds } \\
\quad 4.2\end{array}$ & $\begin{array}{l}\text { Seconds } \\
\quad 3.0\end{array}$ & $\begin{array}{l}\text { Seconds } \\
\quad 2.1\end{array}$ & $\begin{array}{l}\text { Seconds } \\
1.0\end{array}$ \\
\hline
\end{tabular}

The authors express their appreciation to other members of the staff of the National Bureau of Standards for assistance rendered during the various phases of the preparation of this paper. Edgar D. Watts assisted in the design of the test chart and made the drawings used to illustrate this paper. Walter R. Darling and William P. Tayman made measurements on the engraved chart to insure its accuracy. Fred W. Rosberry, Roland V. Shack, and William P. Tayman assisted in assembling the photographic equipment, made the necessary charts and chart holders, made and read the test negatives that are used in describing the test methods and results.

\section{References}

[1] A test of lens resolution for the photographer. I. C. Gardner, NBS Circular 428 (1941).

[2] Charts for testing lens resolution, NBS Miscellaneous Publication M166 (1940).

[3] Compensation of the aperture ratio markings of a photographic lens for absorption, reflection, and vignetting losses. I. C. Gardner. J. Research NBS 38, 643 (1947) RP1803, 10 cents; J. Soc. Mot. Pict. Eng. 49, 96 (August 1947).

[4] Sources of error in and calibration of the F-number of photographic lenses. F. E. Washer. J. Research NBS 41, 301 (1948) RP1927; Soc. Mot. Pict. Eng. 51, 242 (1948).

[5] Precision camera for testing lenses. I. C. Gardner and F. A. Case. J. Research NBS 18, 449 (1937) RP984.

[6] Resolving power and distortion of typical airplanecamera lenses. F. E. Washer. J. Research NBS 22, 729 (1939) RP1216.

[7] Characteristics of wide-angle airplane-camera lenses. F. E. Washer. J. Research NBS 29, 233 (1942) RP498.

[8] Spurious resolution of photographic lenses. R. N. Hotchkiss, F. E. Washer, and F. W. Rosberry, J. Opt. Soc. Am. 41, 600 (1951).

[9] C. W. Kendall and B. A. Schumacher, Photo Technique 3, No. 4, 51 (1941).

[10] E. W. H. Selwyn and J. L. Tearle, Proc. Phys. Soc. LVIII, 493 (1946).

[11] L. E. Howlett, Can. J. Research 24, Sec. A, No. 4, 15 (1946).

[12] New resolving power test chart. F. E. Washer and F. W. Rosberry. J. Opt. Soc. Am. 41, 597 (1951).

[13] Research and development in applied optics and optical glass at the National Bureau of Standards. A review and bibliography. I. C. Gardner and C. H. Hahner. NBS Miscellaneous Publication 194 (1949).

[14] J. I. Crabtree, Trans. Soc. Motion Picture Engrs. 11, 77-87 (1927).

[15] J. I. Crabtree and B. W. Henn, Am. Phot. 33, 78 (1939).

[16] Region of usable imagery in airplane-camera lenses. F. E. Washer. J. Research NBS 34, 175 (1945) RP1636.

Washington, August 14, 1952. 



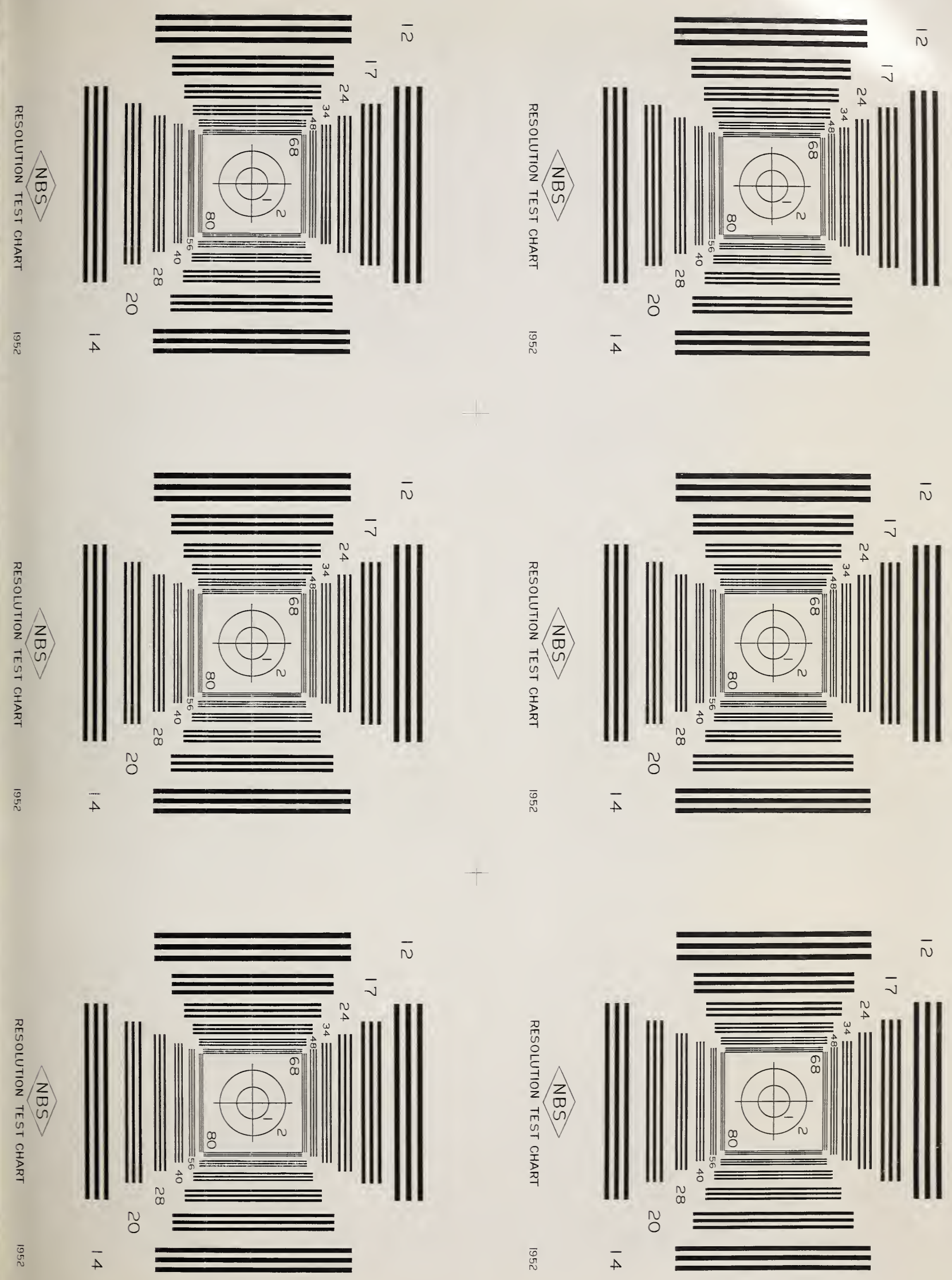


\section{Periodicals of the National Bureau of Standards}

As the principal agency of the Federal Government for fundamental research in physics, chemistry, mathematics, and engineering, the National Bureau of Standards conducts projects in fifteen fields: electricity, optics and metrology, heat and power, atomic and radiation physics, chemistry, mechanics, organic and fibrous materials, metallurgy, mineral products, building technology, applied mathematics, electronics, ordnance development, radio propagation, and missile development. The Bureau has custody of the national standards of measurement and conducts research leading to the improvement of scientific and engineering standards and of techniques and methods of measurement. Testing methods and instruments are developed; physical constants and properties of materials are determined; and technical processes are investigated.

\section{Journal of Research}

Internationally known as a leading scientific periodical, the Journal presents research papers by authorities in the specialized fields of physics, mathematics, chemistry, and engineering. Complete details of the work are presented, including laboratory data, experimental procedures, and theoretical and mathematical analyses. Each of the monthly issues averages 85 two-column pages; illustrated. Annual subscription: domestic, $\$ 5.50$; foreign, $\$ 6.75$.

\section{Technical News Bulletin}

Summaries of current research at the National Bureau of Standards are published each month in the Technical News Bulletin. The articles are brief, with emphasis on the results of research, chosen on the basis of their scientific or technologic importance. Lists of all Bureau publications during the preceding month are given, including Research Papers, Handbooks, Applied Mathematics Series, Building Materials and Structures Reports, and Circulars. Each issue contains 12 or more two-column pages; illustrated. Annual subscription: domestic, $\$ 1.00$; foreign $\$ 1.35$.

\section{Basic Radio Propagation Predictions}

The Predictions provide the information necessary for calculating the best frequencies for communication between any two points in the world at any time during the given month. The data are important to all users of long-range radio communications and navigation, including broadcasting, airline, steamship, and wireless services, as well as to investigators of radio propagation and ionosphere. Each issue, covering a period of one month, is released three months in advance and contains 16 large pages, including pertinent charts, drawings, and tables. Annual subscription: domestic, $\$ 1.00$; foreign, $\$ 1.25$. 
<smiles>[CH]C</smiles> 